\title{
Hypoxia-inducible factor signaling in pulmonary hypertension
}

\author{
Soni Savai Pullamsetti, ${ }^{1,2}$ Argen Mamazhakypov, ${ }^{1}$ Norbert Weissmann, ${ }^{2}$ Werner Seeger, ${ }^{1,2,3}$ and Rajkumar Savai ${ }^{1,2,3,4}$ \\ 'Department of Lung Development and Remodeling, Max Planck Institute for Heart and Lung Research, member of the German Center for Lung Research (DZL), member of the Cardio-Pulmonary Institute \\ (CPI), Bad Nauheim, Germany. ${ }^{2}$ Department of Internal Medicine, Universities of Giessen and Marburg Lung Center, member of the DZL and CPI, Justus Liebig University, Giessen, Germany. ${ }^{3}$ nstitute for \\ Lung Health (ILH), Justus Liebig University, Giessen, Germany. ${ }^{4}$ Frankfurt Cancer Institute (FCI), Goethe University, Frankfurt am Main, Germany
}

Pulmonary hypertension ( $\mathrm{PH})$ is characterized by pulmonary artery remodeling that can subsequently culminate in right heart failure and premature death. Emerging evidence suggests that hypoxia-inducible factor (HIF) signaling plays a fundamental and pivotal role in the pathogenesis of PH. This Review summarizes the regulation of HIF isoforms and their impact in various PH subtypes, as well as the elaborate conditional and cell-specific knockout mouse studies that brought the role of this pathway to light. We also discuss the current preclinical status of pan- and isoform-selective HIF inhibitors, and propose new research areas that may facilitate HIF isoform-specific inhibition as a novel therapeutic strategy for PH and right heart failure.

\section{HIF signaling and biology}

The transcription factor hypoxia-inducible factor (HIF) is a master regulator of oxygen homeostasis that acts as a heterodimeric complex composed of the oxygen-sensitive $\alpha$ subunit (HIF- $\alpha$; including HIF- $1 \alpha$, HIF- $2 \alpha$ [EPAS1], and HIF- $3 \alpha$ ) and the oxygen-insensitive $\beta$ subunit (HIF- $\beta$; including HIF-1 $\beta$ [aryl hydrocarbon receptor nuclear translocator, ARNT1], ARNT2, and ARNT3) (1). In oxygenized cells, the HIF- $\alpha$ subunit is inactivated via hydroxylation by prolyl hydroxylase domain proteins (PHDs) and factor inhibiting HIF (FIH), which allows the binding of von Hippel-Lindau (VHL) tumor suppressor protein, a component of an E3 ubiquitin ligase complex that subsequently targets hydroxylated HIF- $\alpha$ for proteasomal degradation. Under hypoxic conditions, oxygen becomes limited, leading to the attenuation of HIF- $\alpha$ hydroxylation and resulting in stabilization of HIF- $\alpha$ subunits. This initiates nuclear translocation and binding of the HIF- $\alpha$ subunit with the HIF- $\beta$ subunit, and this activated HIF initiates an adaptive response to hypoxia by inducing or repressing a broad range of genes involved in regulation of vascular tone, angiogenesis, erythropoiesis, cellular metabolism, proliferation, survival, and autophagic response (1). However, nonhypoxic conditions, i.e., growth factors, hormones, or cytokines, also modulate HIF- $\alpha$ subunits at various levels (gene transcription, mRNA processing, protein-protein interactions, and posttranslational modifications; for a detailed description see refs. 1, 2) and regulate a plethora of signaling pathways. In the lung, HIFs orchestrate a physiological response to hypoxia and contribute to the pathogenesis of numerous disorders, including lung cancer, chronic obstructive pulmonary disease (COPD), pulmonary fibrosis $(\mathrm{PF})$, and pulmonary hypertension.

Conflict of interest: The authors have declared that no conflict of interest exists. Copyright: () 2020, American Society for Clinical Investigation.

Reference information: J Clin Invest. 2020;130(11):5638-5651.

https://doi.org/10.1172/JCl137558.

\section{Regulation of HIF signaling pathways} in $\mathrm{PH}$ patients

Pulmonary hypertension $(\mathrm{PH})$ is a severe pulmonary vascular disorder characterized by excessive proliferation of vascular cells, increased extracellular matrix deposition, and accumulation of inflammatory cells within the pulmonary vascular wall, collectively resulting in increased pulmonary vascular resistance (3). Despite extensive research in this field, the mechanisms underlying disease development and progression are incompletely understood (4). Among many dysregulated signaling pathways, HIF signaling has been identified as one underlying mechanism determining disease progression not only in pulmonary arterial hypertension (PAH; group I PH), but also in PH due to lung diseases and/or hypoxia, including PH associated with chronic high altitude exposure $(5,6), \mathrm{COPD}(7)$, and PF (8) (group III PH). Notably, augmented expression of HIF-1 $\alpha$ has been observed in lung tissues of patients with PAH (9-13), chronic thromboembolic PH (14), and idiopathic PF-associated PH $(15,16)$, while HIF- $2 \alpha$ has been associated with congenital diaphragmatic hernia-associated PH (17). In addition, neonatal patients with acute respiratory disease-associated PH also display increased circulating levels of HIF-1 $\alpha$ (18). Moreover, HIF-1 $\alpha$ and its target genes vascular endothelial growth factor $(V E G F)$ and erythropoietin $(E P O)$ are upregulated in peripheral blood cells of newborns with cyanosis and persistent $\mathrm{PH}$, therefore representing early markers of generalized hypoxia (19). Similarly, increases in circulating bone marrow-derived progenitor cells observed in PAH patients are regulated by HIF-1 $\alpha$-driven C-X-C motif chemokine ligand 12 (CXCL12) expression in pulmonary artery endothelial cells (PAECs) (20). The cellular sources of increased HIF-1 $\alpha$ expression in lung tissue of PH patients are PAECs $(16,21)$ and pulmonary artery smooth muscle cells (PASMCs) $(22,23)$. While some reports show HIF-1a upregulation in the pulmonary arteries of PAH patients (24), others provide evidence of decreased HIF-1 $\alpha$ in PASMCs isolated from idiopathic PAH (IPAH) patients $(25,26)$. PAH patients also display increased 


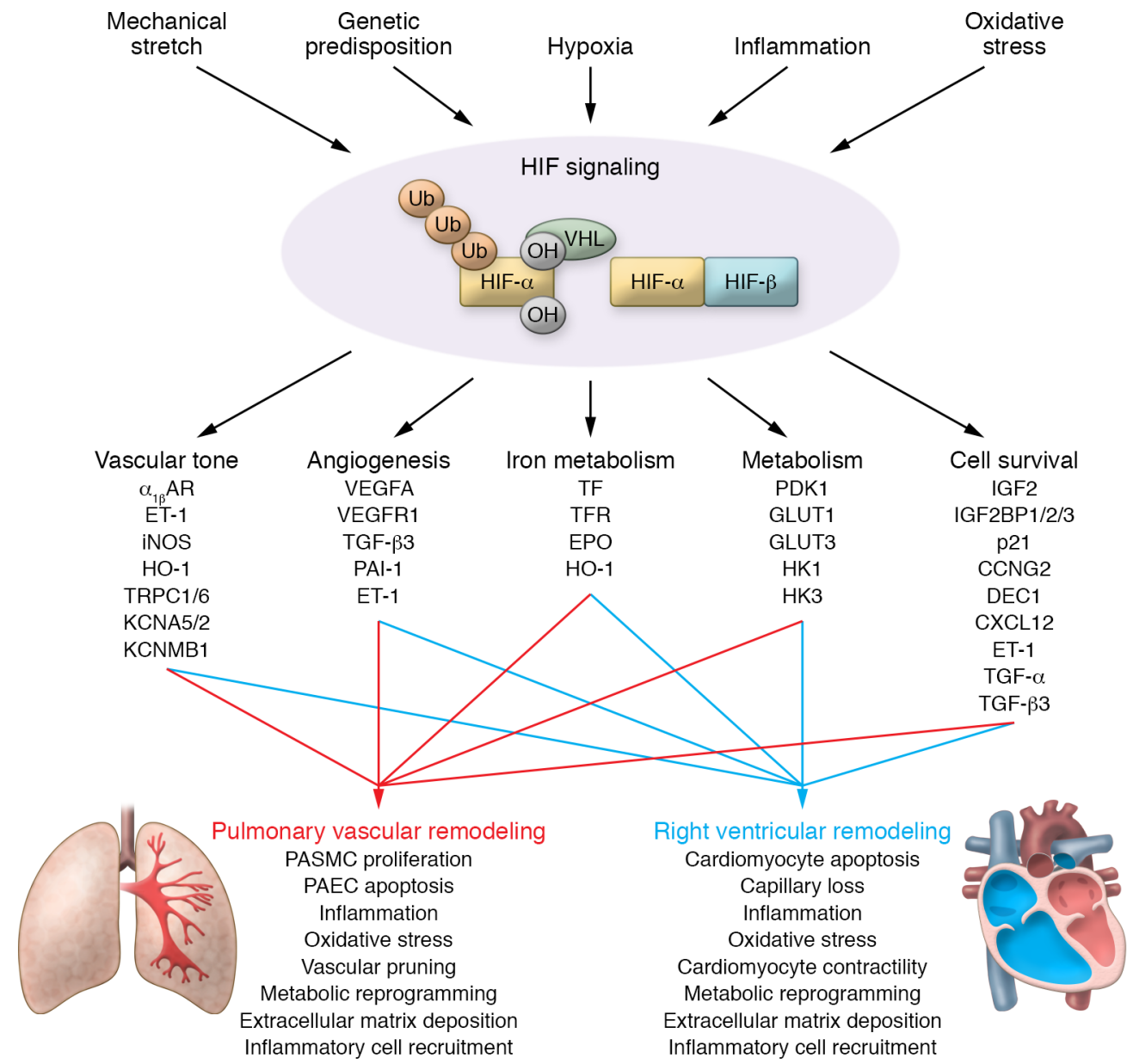

Figure 1. Emerging concepts of HIF signaling in pulmonary hypertension. Emerging evidence shows that many pro-PH factors apart from hypoxia, such as inflammation, mechanical stretch, oxidative stress, and genetic predisposition, converge on HIF signaling pathways, causing alterations in vascular tone, angiogenesis, metabolism, and cell survival that subsequently lead to pulmonary vascular and right ventricular remodeling. VHL, von Hippel-Lindau tumor suppressor; $\alpha_{1 \beta} A R, \alpha_{1} \beta$-adrenergic receptor; iNOS, inducible nitric oxide synthase; HO-1, heme oxygenase-1; TRPC1, transient receptor potential canonical 1; KCNA5, potassium voltage-gated channel, shaker-related subfamily, member 5; KCNMB1, calcium-activated potassium channel subunit beta-1; PAI-1, plasminogen activator inhibitor-1; TF, transferrin; TFR, transferrin receptor; EPO, erythropoietin; PDK1, pyruvate dehydrogenase kinase 1; IGF2BP1, insulin-like growth factor 2 mRNA-binding protein 1; p21, cyclin-dependent kinase inhibitor 1; CCNG2, cyclin-G2; DEC1, deleted in esophageal cancer 1.

pulmonary expression of HIF-1 $\beta$ (11), and similarly, the expression of HIF-2 $\alpha$ has been found to be increased in pulmonary arteries of patients with PAH $(24,27)$ and IPF-associated PH (16). The cellular sources of increased HIF-2 $\alpha$ expression in the lung tissue of PH patients are mainly PAECs $(16,27,28)$, suggesting cell type- and context-specific regulation of HIF isoforms in $\mathrm{PH}$.

\section{Upstream regulators of the HIF system in $\mathrm{PH}$}

Activation of HIFs in various subtypes of $\mathrm{PH}$ suggests that along with chronic hypoxia, other factors responsible for the initiation of $\mathrm{PH}$ (gene variants, vasoconstriction, endothelial dysfunction, mitochondrial abnormalities, dysregulated cell growth, and inflammation) can activate HIF signaling pathways to trigger alterations in pulmonary vascular cells, inflammatory cells, and cardiac cells that remodel lung vasculature and right ventricle (RV) (Figure 1).

Gene variants of the HIF pathway. Gene variants of HIF pathway molecules identified in high-altitude populations and in patients with Chuvash polycythemia illustrate the HIF pathway's importance in pulmonary vascular adaptation and remodeling.
Chuvash polycythemia is characterized by the presence of the R200W (598C >T) missense mutation in VHL, which reduces its binding to hydroxylated HIF- $\alpha$ subunits and thus increases HIF$1 \alpha$ and HIF-2 $\alpha$ levels (29). This leads to expression of HIF target genes including EPO and VEGF and results in development of polycythemia. In Chuvash polycythemia, apart from erythrocytosis, several VHL loss-of-function mutations, including D126N $(376 \mathrm{G}>\mathrm{A})$ (30), D126N $(376 \mathrm{G}>\mathrm{A}) / \mathrm{S} 183 \mathrm{~L} \quad(548 \mathrm{C}>\mathrm{T}) \quad(31)$, and M54I $(162 \mathrm{G}>\mathrm{C})$, were found to be associated with higher resting pulmonary artery pressure (PAP), severe $\mathrm{PH}$, and $\mathrm{RV}$ dysfunction (32-35). Moreover, mutation in HIF-2 $\alpha$ G537R, which impairs HIF- $2 \alpha$ hydroxylation, causing familial erythrocytosis, is also associated with $\mathrm{PH}$ (36).

Several genome-wide selection studies have been performed on high-altitude populations, including Tibetans, Ethiopians, and Andeans $(5,6)$, and identified signals of positive selection for gene variants in and around the HIF pathway enabling these populations to adapt to life at high-altitude hypoxia. However, long-term high-altitude residency may lead to a sustained increase in PAP 


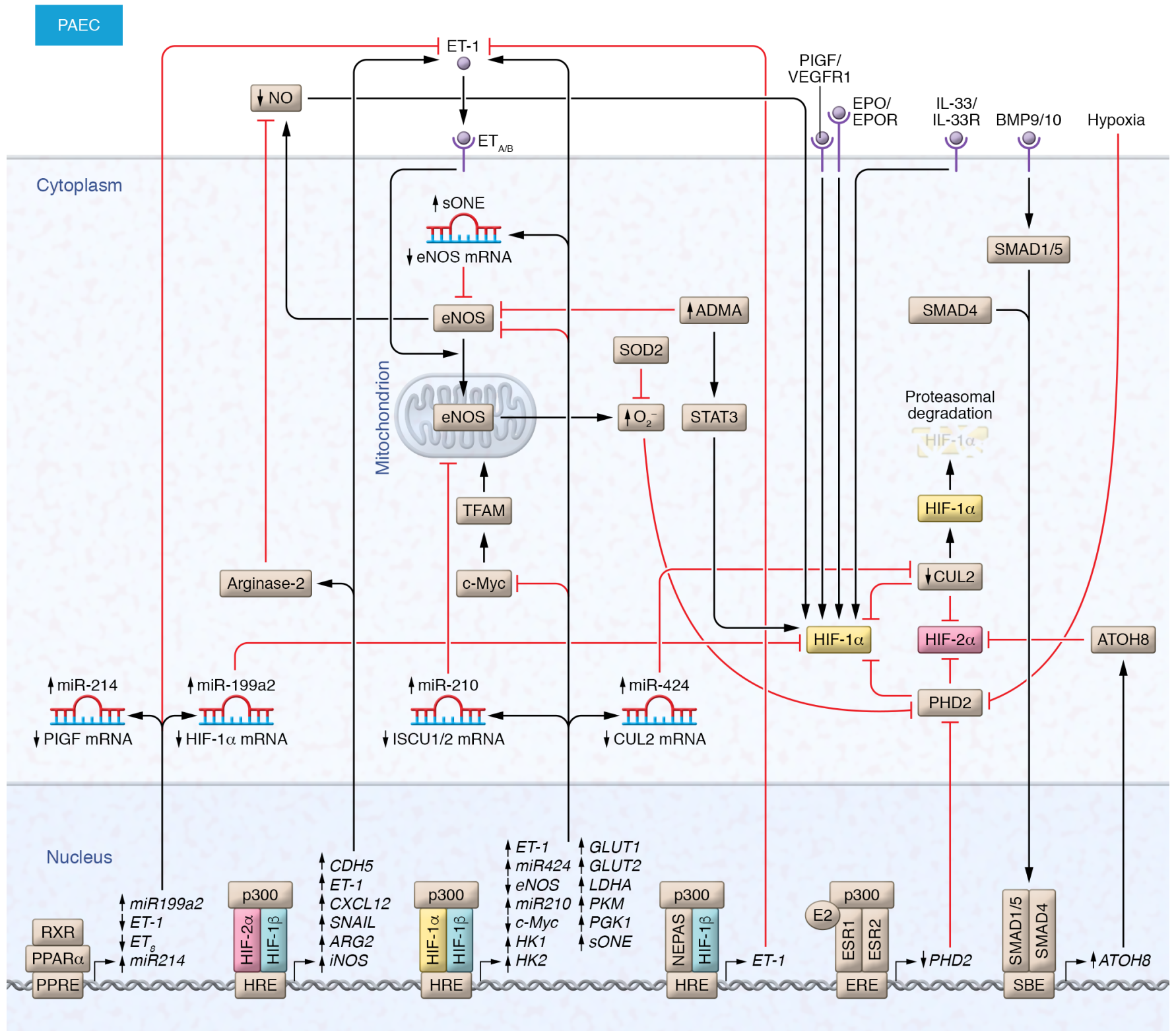

Figure 2. HIF signaling in PH: upstream and downstream modulators in pulmonary artery endothelial cells. Vasomodulatory, mitochondrial, and inflammatory growth factors and epigenetic abnormalities associated with PH regulate HIF isoform stability and transcriptional activity in pulmonary artery endothelial cells (PAECs). Subsequently, HIF isoforms transcriptionally activate a series of genes that participate in vascular tone, angiogenesis, metabolism, and cell proliferation. Long black lines with arrows indicate an activating effect; blocked red lines, an inhibiting effect; $\uparrow$, activation or upregulation; $\downarrow$, inactivation or downregulation. TFAM, mitochondrial transcription factor $\mathrm{A}$; PIGF, placental growth factor; EPOR, erythropoietin receptor; $\mathrm{ET}_{\mathrm{A} / \mathrm{B}}$, endothelin receptor type A and B; sONE, antisense mRNA; ADMA, asymmetric dimethylarginine; Cul2, Cullin 2; ATOH8, atonal BHLH transcription factor 8; ISCU1/2, iron-sulfur (Fe-S) cluster assembly proteins 1 and 2; PGK1, phosphoglycerate kinase 1; PKM, pyruvate kinase M.

and development of PH. Among all high-altitude populations, Tibetans have the lowest PAP (37). A candidate gene study based on the results of genome-wide analyses that identified gene variants associated with high-altitude adaptation found that EPAS1 (HIF-2 $\alpha$ ) variants are associated with lower PAP in Tibetans (38). Furthermore, Tibetans who live at low altitudes but harbor gene variants in EPAS1 (encoding HIF-2 $\alpha$ ) and EGLN1 (encoding PHD2) display blunted hypoxic pulmonary vasoconstriction (39). Thus, future studies are required to delineate the role of HIF pathway gene variants in driving high-altitude $\mathrm{PH}$ susceptibility or resistance among indigenous high-altitude populations.
Vasomodulatory factors. Various vasomodulatory factors have been shown to regulate HIF isoform stability and transcriptional activity in PAECs (Figure 2 and Table 1). Nitric oxide (NO) maintains pulmonary vascular tone, and its downregulation is implicated in $\mathrm{PH}$ pathogenesis. Recent studies indicate that the NO plays a central role in hypoxia/HIF axis regulation. For example, in PAECs, hypoxia leads to post-transcriptional negative regulation of endothelial NO synthase (eNOS) expression by the cis-natural antisense RNA sONE (40), which results in lower levels of NO and increased HIF-1 $\alpha$ stability. Accordingly, low levels of NO due to eNOS deletion also cause HIF-1 $\alpha$ stabilization and migration 
Table 1. Summary of studies investigating upstream regulators of HIF signaling pathway in PH

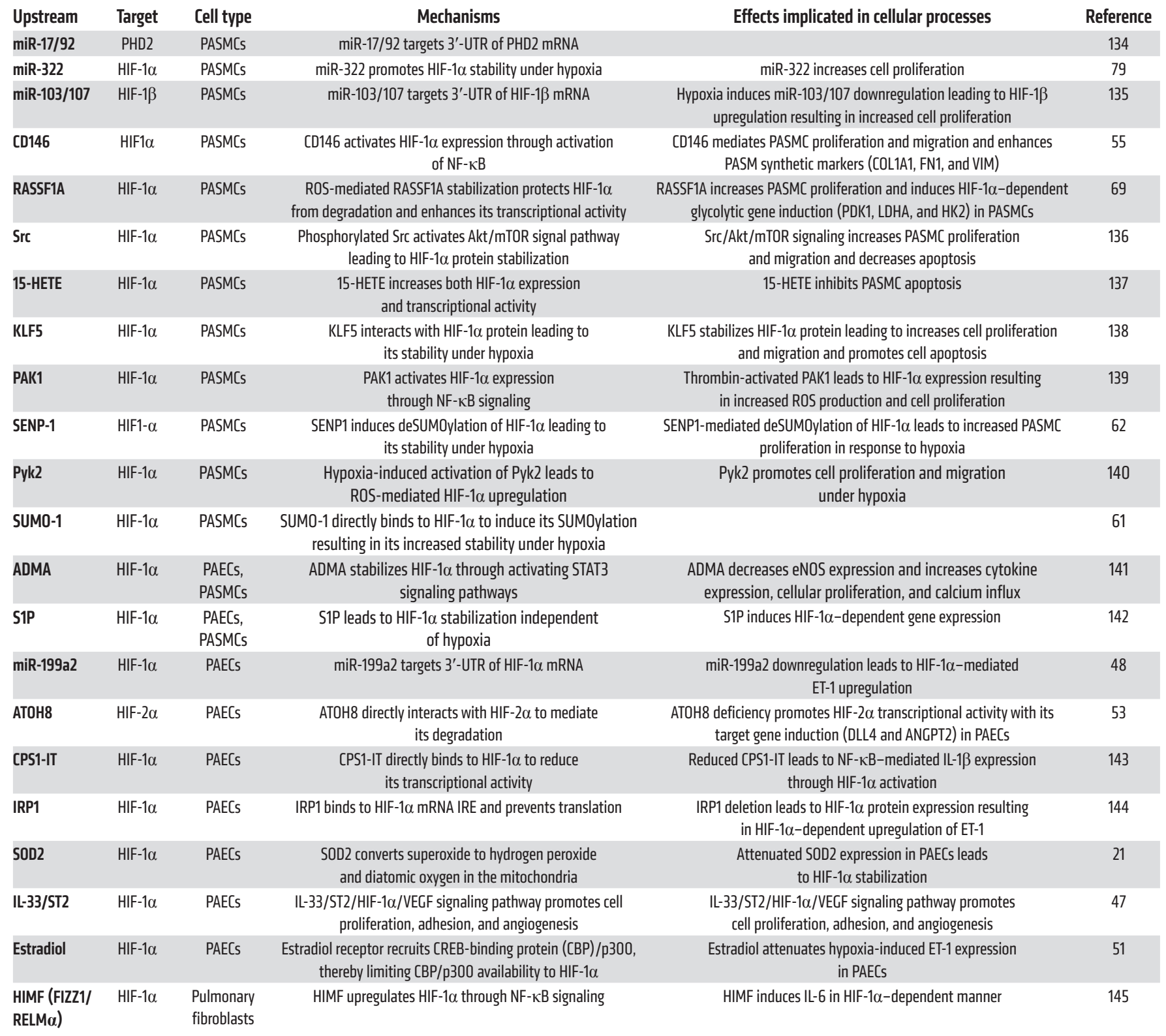

of normoxic endothelial cells (ECs) (41). Moreover, endogenous regulators of NO production such as arginase-2 and asymmetric dimethyl arginine affect cell proliferation and inflammatory gene expression by stabilizing HIF-1 $\alpha$ in PAECs (42). Endothelin 1 (ET-1), a potent vasoconstrictor, also stabilizes HIF-1 $\alpha$, which in turn promotes the HIF- $1 \alpha$-induced glycolytic switch via eNOS-mediated reactive oxygen species (ROS) production in PAECs (43). Likewise, stimulation of normoxic PASMCs with ET-1 increases stability of HIF- $1 \alpha$ as a result of increased $\mathrm{Ca}^{2+}$ and ROS and increases transcriptional activity of HIF-1 $\alpha$ due to ERK1/2 pathway activation, which phosphorylates p300 to increase its binding to HIF-1 $\alpha$ (44). Moreover, ET-1 promotes HIF-1 $\alpha$ protein stabilization in normoxic PASMCs via calcineurin-dependent RACK1 dephosphorylation, which in turn inhibits PHD2 activity (45). Importantly, HIF has also been shown to regulate ET-1 synthesis. Mice with global deficiency for NEPAS, a transcript variant of HIF-3 $\alpha$, exhibit ET-1 overexpression, which leads to pulmonary vascular remodeling and dilated cardiomyopathy due to excessive tissue vascularization that is evident from birth and progresses in later stages of life (46). Thus, HIF and ET-1 form a bidirectional regulatory loop that plays an important role in driving pulmonary vascular remodeling.

Inflammation, growth factors, and microRNAs. Hypoxia induces upregulation of IL-33 and its receptor ST2 in PAECs, which activates downstream HIF-1 $\alpha$ /VEGF signaling resulting in enhanced proliferation, adhesion, and angiogenesis in an ST2-dependent fashion (47). Similarly, hormones and growth factors such as bone morphogenetic protein (BMP), placental growth factor (PlGF), platelet-derived growth factor (PDGF), EPO, estradiol, and sig- 
naling molecules regulate HIF isoform transcriptional activity in PAECs. For example, in patients with sickle cell disease-associated (SCD-associated) PH, elevated levels of PlGF result in downregulation of microRNA-199a2 (miR-199a2), a negative regulator of HIF- $1 \alpha$. Furthermore, PPAR $\alpha$ agonist-mediated transcription of miR-199a2 attenuates ET-1 expression and HIF-1 $\alpha$ level, ameliorating $\mathrm{PH}$ in a mouse model of SCD (48-50). Estradiol negatively regulates ET-1 expression in PAECs by interfering with HIF activity, possibly through competition for limiting quantities of $\mathrm{CBP} /$ p300 (51). Estradiol also negatively regulates HIF-2 $\alpha$ by promoting its degradation by estrogen receptor $\beta$-mediated (ER $\beta$-mediated) PHD2 upregulation in hypoxic PAECs (52). By contrast, the BMP signaling molecules SMAD1 and SMAD5 transcriptionally activate atonal bHLH transcription factor 8 ( $A T O H 8)$ expression, which interacts with HIF- $2 \alpha$ to reduce its abundance and expression of its target genes delta-like protein 4 (DLL4) and angiopoietin-2 (ANGPT2) in hypoxia-exposed PAECs (53). ATOH8-KO mice spontaneously develop $\mathrm{PH}$, suggesting an important role for BMP signaling in regulating the HIF pathway. Moreover, HIF- $1 \alpha$-driven expression of miR-322/424 in human ECs attenuates HIF- $1 \alpha$ degradation by causing post-transcriptional repression of cullin-2, an E3 ubiquitin ligase scaffolding protein (54).

However, with regard to PASMCs, cross-regulation between the adhesion molecule CD146 and HIF- $1 \alpha$ via the NF- $\kappa$ B pathway in PASMCs has been shown to trigger pulmonary vascular remodeling. Disruption of the CD146/HIF-1 $\alpha$ axis in PASMCs blunts vascular remodeling and produces a marked attenuation of PH (55). Furthermore, exaggerated proliferation in PASMCs occurs after exposure to growth factors, such as epidermal growth factor (EGF), FGF2, PDGF, or is mediated by HIF- $1 \alpha$ but not HIF- $2 \alpha$ activation (56), suggesting that HIF-1 $\alpha$ acts downstream of these growth factors, which are well established as disease-driving factors in PH. PPAR $\gamma$ agonists exert antiproliferative effects on PASMCs via PPAR $\gamma$-mediated inhibition of HIF- $1 \alpha$ and its downstream genes such as PDK-1, TRPC1, and TRPC6 $(57,58)$. However, hypoxia induces PPAR $\gamma$ downregulation via HIF- $1 \alpha$ in PASMCs $(57,58)$, suggesting a negative feedback loop mechanism between PPAR $\gamma$ and HIF-1 $\alpha$. Among other regulators, hypoxia-induced downregulation of miR-206 (59) and miR-150 (60) promotes a pro-proliferative and promigratory phenotype of PASMCs by targeting HIF- $1 \alpha$. Furthermore, in rat PASMCs, upregulation of molecules related to both SUMOylation (SUMO-1) and deSUMOylation (SENP1) leads to increased HIF-1 $\alpha$ stability and transcriptional activity, thus increasing proliferation $(61,62)$.

Mitochondrial abnormalities. The interplay between mitochondrial abnormalities, NADPH oxidases (NOXs), and ROS has been established as an important activator of HIF- $1 \alpha$ in pulmonary vascular cells in PH (63-65). For example, mitochondrial abnormalities that shift metabolism away from oxidative phosphorylation toward glycolysis (notably pyruvate dehydrogenase kinase [PDK] activation) lead to a normoxic impairment of electron flux and reduced mitochondrial ROS production (66). This pseudohypoxic signal is associated with nuclear translocation of HIF- $1 \alpha$. On the contrary, reports suggest that low levels of superoxide dismutase 2 (SOD2), as observed in PAECs from patients with IPAH, promote HIF- $1 \alpha$ stabilization due to increased ROS levels (21). Mechanical stretch imposed on PASMCs due to pul- monary hemodynamic stress causes mitochondrial complex IIImediated ROS formation, which both induces the NF- $\kappa B$ pathway and inhibits Phd2, leading to HIF-1 $\alpha$ activation (67), indicating that hemodynamic stress itself serves as an independent regulator of HIF-1 $\alpha$. Indeed, several molecules that are upstream regulators of ROS are implicated in HIF-1 $\alpha$ activation. For instance, loss of sirtuin 3, a crucial regulator of mitochondrial function in PASMCs, causes mitochondrial dysfunction leading to ROS production and HIF-1 $\alpha$ stabilization (68). As a consequence, sirtuin 3-KO mice develop spontaneous PH and RV hypertrophy (68). Recently, we identified a molecular mechanism in which a scaffold protein, Ras association domain family 1A (RASSF1A), acts as a crucial regulator of HIF- $1 \alpha$ signaling in PASMCs. Upon hypoxia, HIF-1 $\alpha$ upregulates RASSF1A expression, and RASSF1A is stabilized by ROS-driven and protein kinase C-mediated (PKC-mediated) phosphorylation. RASSF1A in turn stabilizes HIF-1 $\alpha$, leading to increased HIF-1 transcriptional activity (69). This crucial RASSF1A-HIF-1 $\alpha$ feed-forward loop determines pro-proliferative and glycolytic switch of PASMCs and pulmonary artery adventitial fibroblasts (PAAFs) (69). Disruption of RASSF1A/HIF-1 $\alpha$ crosstalk by genetic ablation of RASSF1A mitigates pulmonary vascular remodeling in mice exposed to chronic hypoxia.

\section{HIFs' role in $\mathrm{PH}$-associated cellular and molecular abnormalities}

Under extended exposure to reduced oxygen levels in pulmonary vascular cells, HIF isoforms transcriptionally activate a series of genes (Figures 2 and 3) that regulate vascular tone, angiogenesis, metabolism, and proliferation. Moreover, recent studies highlighted the potential role of HIFs and the underlying molecular mechanisms in the dysregulation of the innate and adaptive immune system in $\mathrm{PH}$.

PAECs. PAECs exhibit different phenotypes (proliferative, migratory, angiogenic, and/or endothelial-mesenchymal transition [EndoMT]) during PH pathogenesis, and HIF isoforms play a decisive role in defining these phenotypes. For example, HIF-1 induces cyclin-dependent kinase inhibitor 1B ( $\left.p 27^{\text {Kip } 1}\right)$ upregulation and cyclin D1 downregulation, leading to decreased proliferation and migration of hypoxic PAECs (70). By contrast, HIF-2-driven octamer-binding transcription factor 4 (OCT4) expression via miR-130/131-mediated downregulation of PPAR $\gamma /$ apelin signaling results in increased proliferation of PAECs (71). In addition, both HIF- 1 and HIF-2 in PAECs contribute to altered metabolic phenotype by modulating the expression of distinct mitochondrial enzymes such as pyruvate dehydrogenase kinase 1 (PDK1), hexokinase 1,2 (HK1,2), lactate dehydrogenase A ( $L D H A)$, and glucose transporter 1,3 (GLUT1,3) to regulate anaerobic glycolysis and the Warburg effect (aerobic glycolysis). The influence of HIF-1 on glycolytic metabolism is well established (72); the Warburg effect in IPAH could possibly be driven by HIF- $1 \alpha$ stabilization, independently of the hypoxic environment. On the other hand, HIF-2, but not HIF-1, by upregulating SNAI1 transcription factors, triggers EndoMT, a mechanism potentially involved in the development of occlusive intimal/neointimal lesions and severe pulmonary vascular wall thickening in IPAH (28). Furthermore, EC HIF-2 influences the development of hypoxic $\mathrm{PH}$ via an arginase-1-dependent mechanism. The HIF-2/arginase-1 axis dysregu- 


\section{PASMC}

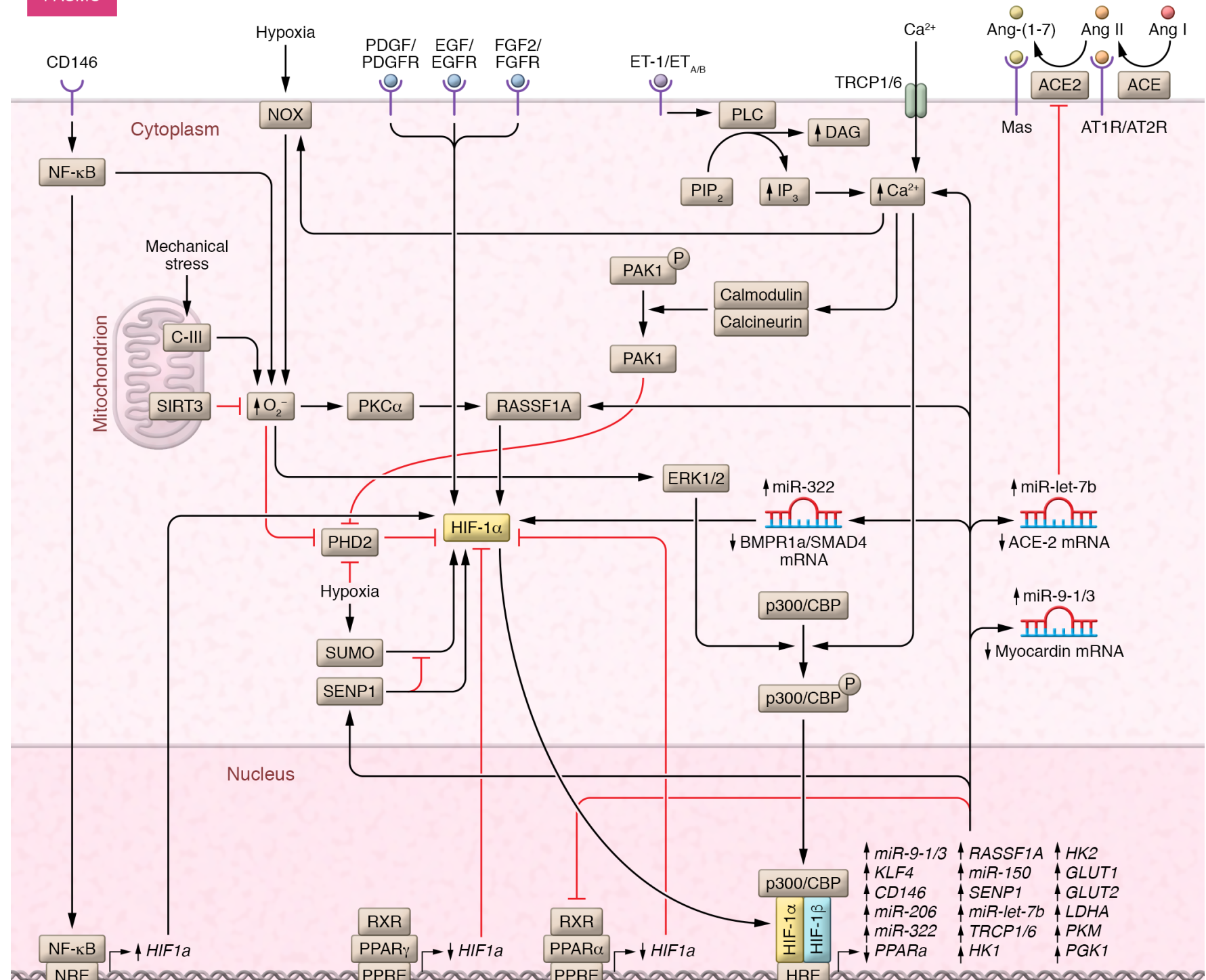

Figure 3. HIF signaling in PH: Upstream and downstream modulators in pulmonary artery smooth muscle cells. Signaling pathways associated with $\mathrm{PH}$ such as hypoxia, vasomodulation, growth factors, mechanical stress, and oxidative stress pathways regulate HIF isoform stability and transcriptional activity in PASMCs. This regulates genes related to cell proliferation and synthetic phenotypes, as well as genes related to Ca2+ modulation/ion channels, oxidative stress, mitochondrial fragmentation, and the renin-angiotensin-aldosterone system (RAAS) system. Long black lines with arrows indicate an activating effect; blocked red lines, an inhibiting effect; $\uparrow$, activation or upregulation; $\downarrow$, inactivation or downregulation. C-III, mitochondrial complex III; SIRT3, Sirtuin 3; TRPC6, transient receptor potential cation channel subfamily C member 1 or 6; FCFR, fibroblast growth factor receptor; Ang-I, angiotensin I; Ang-II, angiotensin II; Ang-(1-7), angiotensin (1-7); Mas, Ang-(1-7) receptor; ATR1/2, angiotensin receptor type 1 and 2; ACE, angiotensin converting enzyme; PIP2, phosphatidylinositol 4,5-bisphosphate; IP3, inositol trisphosphate; DAG, diacylglycerol; 02-, superoxide anion; PKC $\alpha$, protein kinase $C$ alpha; PAK1, P21 activated kinase 1; SENP-1, sentrin-specific protease 1.

lates vascular NO homeostasis $(73,74)$, resulting in $\mathrm{PH}$ in hypoxiaexposed mice (73). Consequently, EC arginase-1 loss attenuates $\mathrm{PH}$ in hypoxia-exposed mice (73), and arginase inhibition prevents $\mathrm{PH}$ in monocrotaline-injected (MCT-injected) rats (75). However, the expression of HIF-2-mediated angiopoietin-1 and -2 in ECs is shown to be essential to maintaining proper pulmonary vascular homeostasis $(76,77)$. These data propose that HIF-1 and HIF-2 exert pathogenic roles in PH by regulating distinct cellular processes in PAECs.
PASMCs. In PASMCs, HIF isoforms regulate not only genes related to cell proliferation and synthetic phenotypes but also genes related to vasoconstriction $\left(\mathrm{Ca}^{2+}\right.$ modulation/ion channels), oxidative stress, mitochondrial fragmentation, and the renin-angiotensinaldosterone system (Figure 3). Increased PASMC proliferation and the prosynthetic phenotypic switch observed in hypoxia are mediated by HIF-1-driven expression of miR-9-1 and miR-9-3, which negatively regulate myocardin (MYOCD) expression (78). Augmented proliferation of rat PASMCs is associated with inhibition of the BMP 
pathway as a result of HIF-1-induced, but not HIF-2-induced, miR322, which causes posttranslational repression of Bmpr1a and Smad5 genes (79). HIF-1-dependent upregulation of miR-210 causes apoptosis resistance in PASMCs by targeting transcription factor E2F3 (80). By contrast, HIF-2 promotes hypoxia-responsive PASMC migration and contractility by upregulating thrombospondin-1 (81). Thus, multiple mechanisms contribute to the pro-proliferative, promigratory, and apoptosis resistance phenotypes of PASMCs. Furthermore, hypoxia-induced muscularization of nonmuscularized pulmonary arterioles involves preexisting smooth muscle cell (SMC) progenitor cells that undergo dedifferentiation, migration to the distal vessel, proliferation, and redifferentiation (82). Elegant studies by Sheikh et al. demonstrated that activation of these progenitor cells starts with HIF- $1 \alpha$-mediated PDGF- $\beta$ expression (83), and progresses with expansion of these progenitor-derived SMCs via HIF-1 $\alpha$-mediated Krüppel-like factor 4 (KLF4) expression (84). These studies demonstrate a central role of HIF-1 in the initiation as well as progression of pulmonary artery muscularization in hypoxia-induced $\mathrm{PH}$.

Changes in intracellular $\mathrm{K}^{+}$and intracellular $\mathrm{Ca}^{2+}$ concentration $\left(\left[\mathrm{Ca}^{2+}\right]_{\mathrm{i}}\right)$ play a pivotal role in the regulation of contraction, migration, and proliferation of PASMCs (2). Notably, HIF-1 plays an essential role in modulating $\left[\mathrm{Ca}^{2+}\right]_{\mathrm{i}}$ levels in PASMCs by regulating the expression of various ion channels. HIF-1 promotes overexpression of the transient receptor potential (TRPC) channel members TRPC1 and TRPC6 and subsequently increases $\left[\mathrm{Ca}^{2+}\right]_{i}$ in hypoxic PASMCs (85). In addition, HIF-1 via ET-1 represses voltage-gated $\mathrm{K}^{+}$channels members that subsequently also increase $\left[\mathrm{Ca}^{2+}\right]_{\mathrm{i}}(86)$. On the other hand, HIF-1 activates expression of the $\beta_{1}$ subunit (KCNMB1) of the calcium-sensitive $\mathrm{K}^{+}$channel $\mathrm{BKCa}$, which prevents an excessive rise in $\left[\mathrm{Ca}^{2+}\right]_{i}$ in PASMCs (87).

PAAFs. Although both HIF- $1 \alpha$ and HIF- $2 \alpha$ are activated in PAAFs in response to hypoxia, HIF- $2 \alpha$ induction appears to play the dominant role in the proliferation response, whereas both HIF-1 and HIF-2 increase PAAF migration to a similar extent (88). Furthermore, studies suggest that HIF-1 via the regulation of $A C E$ and ACE2 (a homolog of ACE that counterbalances the function of ACE) directly participates in the regulation of the renin-angiotensinaldosterone system and consequently PAAF proliferation (89-91).

Inflammatory cells. Immune cells play an essential role in pulmonary vascular remodeling by regulating the functions of pulmonary vascular cells (92). For example, hypoxic PAAFs drive profibrotic macrophage phenotypes under the control of HIF-1, resulting in the release of various paracrine factors. Importantly, macrophage-produced VEGF and IL- 6 are shown to promote pulmonary vascular remodeling (12).

\section{The role of the HIF system in pulmonary vascular remodeling}

Considering the multitude of cellular and mechanistic roles of the HIF pathway, it is not surprising that knockout mouse models of the HIF pathway (Hifl/2 $\alpha, V H L$, and $P h d 2)$ provided valuable insights on the HIF pathway in the hypoxic adaptation of the pulmonary vasculature and the development of PH (Table 2). Earlier studies revealed that the genes of the HIF pathway are crucial for embryonic development and that biallelic deletion of the majority of those genes is lethal. For example, homozygous deletion of $P h d 2$ in mice leads to embryonic lethality, although $P h d 1 / 3$ double knockout leads to viable and fertile mice (93). Complete deletion of Hif1a (94), Hif2a (95), or Hif1b (96) in mice results in embryonic lethality due to various developmental defects. In contrast, mice with global heterozygous deletion of either Hifla or Hif2a reach adulthood and do not display phenotypes in homeostatic conditions, making them useful to study the role of HIFs in disease. For example, mice with heterozygous deletion of Hifla exhibit attenuated PH and RV hypertrophy upon hypoxia exposure (97). By contrast, mice with heterozygous deletion of Hif2 $a$ are completely protected from hypoxia-induced $\mathrm{PH}$ (98). Further, to evaluate how global deletion of HIF isoforms during adult life affects hypoxia-induced $\mathrm{PH}, \mathrm{Hu}$ et al. showed that global Hifla deletion in mice did not prevent hypoxia-induced $\mathrm{PH}$, whereas mice with global Hif2a deletion did not survive long-term hypoxia (99). Conversely, global partial Hif2a deletion diminishes development of hypoxia-induced $\mathrm{PH}$ at 5 weeks in adult mice (99).

Furthermore, to tease out the cell- and postnatal-specific role of HIF pathway components in $\mathrm{PH}$ pathogenesis, various studies have used constitutive or inducible cell-specific knockout mouse models. For example, Ball et al. reported that SMC-specific postnatal (inducible) deletion of Hifla attenuated PH but did not affect RV hypertrophy (100). Meanwhile, in another study, mice with constitutive SMC-specific Hifla deletion showed exacerbated hypoxia-induced $\mathrm{PH}$ (101). More recent studies demonstrated that mice with constitutive EC-specific Hifla deletion are not protected from hypoxia-induced PH and RV hypertrophy $(28,73)$. However, in another study, mice with inducible EC Hifla deletion were protected from $\mathrm{PH}$ and RV hypertrophy under hypoxia (84). Interestingly, inducible Hifla deletion in either ECs and SMCs did not prevent hypoxia-induced PH and RV hypertrophy (102). In contrast, postnatal deletion of (PDGFR- $\beta^{+}$)/SMC marker ${ }^{+}$progenitors completely prevents $\mathrm{PH}$ and RV hypertrophy in hypoxia-exposed mice (84). With regard to HIF-2 $\alpha$, Skuli et al. reported that mice with EC-specific Hif2a deletion develop PH and RV dilatation (but not RV hypertrophy) due to vascular leakage into the lung parenchyma (103). Similarly, Tang et al. demonstrated that EC-specific deletion of Hif2a, but not Hifla, prevents mice from developing $\mathrm{PH}$ under hypoxic conditions (28). Interestingly, simultaneous deletion of Hifla and Hif2 $a$ in ECs also provides protection against bleomycin-induced $\mathrm{PH}$ and RV hypertrophy despite lung fibrosis development (16). These data suggest that the prominent role of Hif $2 a$ in ECs is critical in the initiation and progression of $\mathrm{PH}$. However, results of EC-specific gene-deletion mouse models should be interpreted cautiously, since, depending on whether a Cre/ERT2 or Cre23 system was used, gene deletion may be exclusively EC-specific or target other cell types, respectively (104).

Notably, multiple groups have shown that mice with Phd2 deletion in ECs spontaneously develop severe PH associated with massive pulmonary vascular lesions and adverse RV remodeling that is evident from the age of 1.5 months $(10,105,106)$. Concomitant deletion of both Phd2 and Hifla or Phd 2 and Hif $2 a$ in ECs identified HIF- $2 \alpha$ activation as a critical downstream modulator of PHD2 deficiency in PH development $(10,105)$. Interestingly, these mice show increased mortality within 6-9 months of age, presumably due to progressive RV failure $(10,105)$. Supporting this role of HIF- $2 \alpha$ activity in the effect of PHD2 deficiency, mice with both heterozygous and homozygous Hif2a G536W gain-of- 
Table 2. Summary of studies evaluating the phenotypes of genetic manipulation of HIF and HIF regulators in animal models of PH

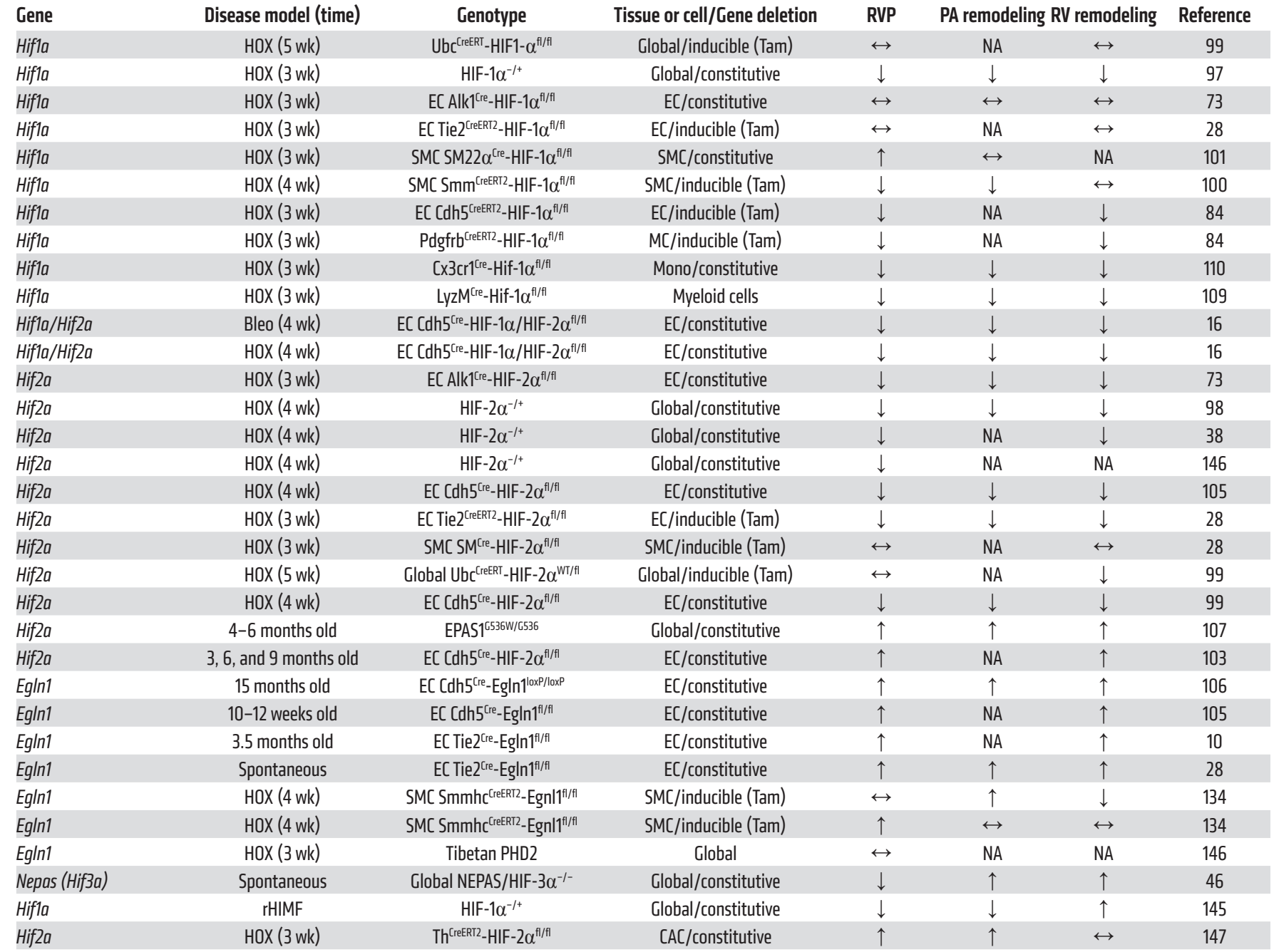

$\uparrow$, Significantly higher compared with WT counterparts; $\downarrow$, significantly lower compared with WT counterparts; $\leftrightarrow$, no difference compared with WT counterparts. Bleo, bleomycin-induced; CAC, catecholaminergic cell; EC, endothelial cell; HOX, hypoxia-exposed; MC, mesenchymal cell; Mono, monocyte; PA, pulmonary artery; RVP, right ventricular systolic pressure; RV, right ventricular; SMC, smooth muscle cell; Tam, tamoxifen.

function mutations develop spontaneous $\mathrm{PH}$ and RV hypertrophy without RV dilatation (107). Furthermore, mice bearing homozygous knockin of a human R200W VHL mutation (as found in patients with Chuvash polycythemia) develop PH (108). Notably, development of $\mathrm{PH}$ in this model is attenuated in the setting of heterozygous deletion of Hif2a, but not of Hifla (108), suggesting a prominent role of HIF- $2 \alpha$ in PH induced by VHL loss of function.

Furthermore, in a study exploring the inflammatory- and immune-specific roles of HIF isoforms in the pathogenesis of $\mathrm{PH}$, mice with EC-specific deletion of Phd2 developed spontaneous PH due to Hif $2 a$ stabilization, which was partially attenuated by transplantation with WT bone marrow-derived cells, suggesting that HIF-2 activation in bone marrow-derived cells contributes to pulmonary vascular remodeling (10). In addition, mice with Hifla deletion in myeloid cells are partially protected from hypoxiainduced PH and RV hypertrophy, mainly as a result of attenuat- ed macrophage activity (109). Similarly, mice with monocytespecific Hifla deletion display attenuated PH, PA remodeling, and RV hypertrophy in response to hypoxia or hypoxia plus Sugen 5416 (SuHx) exposure (110). In addition to myeloid cells, the HIF pathway is also involved in the regulation of lymphoid cells. For example, Hif $2 a$ activation induced by $P h d 2$ deletion causes immunoregulatory dysfunction (111), which may partially explain $\mathrm{PH}$ development associated with reduced regulatory $\mathrm{T}$ cell function (112). Collectively, these studies suggest that both bone marrowderived macrophages and thymus-derived $\mathrm{T}$ cells are involved in pulmonary vascular remodeling at least in part because of HIF pathway activation.

Taken together, global, inducible, and cell-specific deletion of HIF isoforms and HIF pathway molecules established cell typeand context-specific roles of HIF isoforms in early as well as late stages of PH development in adult mice. 
Table 3. Summary of studies evaluating the effects of pharmacological agents targeting HIF signaling in animal models of PH

\begin{tabular}{|c|c|c|c|c|c|c|c|c|}
\hline Agent & $\begin{array}{l}\text { Mechanism } \\
\text { of action }\end{array}$ & $\begin{array}{l}\text { Treatment } \\
\text { option }\end{array}$ & $\begin{array}{l}\text { Disease } \\
\text { model }\end{array}$ & Agent application details & RVP & $\begin{array}{c}\mathrm{PA} \\
\text { remodeling }\end{array}$ & $\begin{array}{c}\mathrm{RV} \\
\text { remodeling }\end{array}$ & Reference \\
\hline R59949 & PHD2 activator & Therapeutic & HOX mice & $\begin{array}{l}\text { Injection (i.p.) daily } 5 \text { days a week, } \\
0.125 \mathrm{mg} / 25 \mathrm{~g} \mathrm{BW}\end{array}$ & $\leftrightarrow$ & $\downarrow$ & $\leftrightarrow$ & 134 \\
\hline 2-ME2 & HIF-1 $\alpha$ inhibitor & Therapeutic & HOX rats & Implantation (s.c.), $60 \mu \mathrm{g} / \mathrm{kg}$ per day & $\downarrow$ & $\downarrow$ & $\downarrow$ & 148 \\
\hline Topotecan & HIF-1 $\alpha$ inhibitor & Preventive & HOX rats & Oral gavage daily, $1 \mathrm{mg} / \mathrm{kg}$ BW & $\downarrow$ & $\downarrow$ & $\downarrow$ & 149 \\
\hline Topotecan & HIF-1 $\alpha$ inhibitor & Preventive & HOX rats & Oral gavage daily, $10 \mathrm{mg} / \mathrm{kg}$ BW & $\downarrow$ & $\downarrow$ & $\downarrow$ & 149 \\
\hline Digoxin & HIF-1 $\alpha$ inhibitor & Preventive & HOX mice & Injection daily, 1.0 mg/kg BW & $\downarrow$ & NA & $\downarrow$ & 150 \\
\hline Anti-CD146 mAb AA98 & HIF-1 $\alpha$ inhibitor & Therapeutic & HOX mice & Injection (i.p.) twice a week, 5 mg/kg BW & $\downarrow$ & $\downarrow$ & $\downarrow$ & 55 \\
\hline Anti-CD146 mAb AA98 & HIF-1 $\alpha$ inhibitor & Therapeutic & MCT rats & Injection (i.p.) twice a week, 5 mg/BW & $\downarrow$ & $\downarrow$ & $\downarrow$ & 55 \\
\hline CAPE & HIF-1 $\alpha$ inhibitor & Therapeutic & MCT rats & Injection (i.p.) daily, 5 or 10 mg/kg BW & $\downarrow$ & $\downarrow$ & $\downarrow$ & 151 \\
\hline Celastramycin & HIF-1 $\alpha$ inhibitor & Preventive & HOX mice & Osmotic pump, 10 mg/kg BW & $\downarrow$ & $\downarrow$ & $\downarrow$ & 22 \\
\hline Celastramycin & HIF-1 $\alpha$ inhibitor & Preventive & MCT rats & Injection (s.c.) daily, $3 \mathrm{mg} / \mathrm{kg} \mathrm{BW}$ & $\downarrow$ & $\downarrow$ & $\downarrow$ & 22 \\
\hline Celastramycin & HIF1 $\alpha$ inhibitor & Therapeutic & SuHx rats & Injection (s.c.) daily, 3 mg/kg BW & $\downarrow$ & $\downarrow$ & $\downarrow$ & 22 \\
\hline$Y C-1$ & HIF-1 $\alpha$ inhibitor & Preventive & HOX mice & Injection (i.p.) daily, 5 mg/kg BW & $\downarrow$ & $\downarrow$ & $\downarrow$ & 152 \\
\hline$Y C-1$ & HIF-1 $\alpha$ inhibitor & Therapeutic & HOX mice & Injection (i.p.) daily, $5 \mathrm{mg} / \mathrm{kg}$ BW & $\downarrow$ & $\downarrow$ & $\downarrow$ & 152 \\
\hline HIF2 $\alpha$-ASO & HIF-2 $\alpha$ inhibitor & Preventive & HOX mice & Injection (i.p.) twice a week, $50 \mathrm{mg} / \mathrm{kg}$ BW & $\downarrow$ & $\downarrow$ & $\downarrow$ & 99 \\
\hline PT2567 & HIF-2 $\alpha$ inhibitor & Preventive & HOX rats & Oral gavage daily, 300 mg/kg BW & $\downarrow$ & $\downarrow$ & $\downarrow$ & 99 \\
\hline C76 & HIF-2 $\alpha$ inhibitor & Preventive & EC Phd2-KO mice & Injection (i.p.) daily, $12.5 \mathrm{mg} / \mathrm{kg}$ BW & $\downarrow$ & $\downarrow$ & $\downarrow$ & 27 \\
\hline C76 & HIF-2 $\alpha$ inhibitor & Therapeutic & SuHx rats & Injection (i.p.) daily, $12.5 \mathrm{mg} / \mathrm{kg} \mathrm{BW}$ & $\downarrow$ & $\downarrow$ & $\downarrow$ & 27 \\
\hline C76 & HIF2 $\alpha$ inhibitor & Therapeutic & MCT rats & Injection (i.p.) daily, 12.5 mg/kg BW & $\downarrow$ & $\downarrow$ & $\downarrow$ & 27 \\
\hline Apigenin & HIF-1 $\alpha$ inhibitor & Preventive & HOX rats & $\begin{array}{c}\text { Oral gavage, daily, } 50 \mathrm{mg} / \mathrm{kg} \text { BW } \\
\text { or } 160 \mathrm{mg} / \mathrm{kg} \mathrm{BW}\end{array}$ & $\downarrow$ & $\downarrow$ & $\downarrow$ & 153 \\
\hline Apigenin & HIF-1 $\alpha$ inhibitor & Therapeutic & HOX rats & $\begin{array}{c}\text { Oral gavage, daily, } 50 \mathrm{mg} / \mathrm{kg} \mathrm{BW} \\
\text { or } 160 \mathrm{mg} / \mathrm{kg} \mathrm{BW}\end{array}$ & $\downarrow$ & $\downarrow$ & $\downarrow$ & 153 \\
\hline
\end{tabular}

$\uparrow$, Significantly higher compared with placebo-treated counterparts; $\downarrow$, significantly lower compared with placebo-treated counterparts; $\leftrightarrow$, no difference compared with placebo-treated counterparts. RVP, right ventricular pressure; PA, pulmonary artery; RV, right ventricle; CAPE, caffeic acid phenethyl ester; EC, endothelial cell; ET, ejection time; HOX, hypoxia-exposed; 2-ME2, 2-methoxyestradiol.

\section{The role of the HIF system in RV remodeling}

$\mathrm{RV}$ failure is one of the most common causes of morbidity and mortality in PAH (113). Upon PH onset, the RV undergoes remodeling to maintain its contractility, characterized by increased RV wall thickness and mass and moderate dilatation, mediated by cardiomyocyte hypertrophy and extracellular matrix deposition. However, at some point during the course of persistent pressure overload, the compensatory mechanisms of the RV expire, and the RV fails (113).

In physiological conditions, HIF-1 $\alpha$ expression is significantly higher in the right than in the left ventricle (114). RV HIF-1 $\alpha$ expression is increased in a number of animal models of $\mathrm{PH}$, including MCT rats (115), hypoxia-exposed (HOX) rats (116), pulmonary artery-banded (PAB) rats (117), SuHx rats (117), and pulmonary embolism (PE) rats (118). Rats with PE display increased RV HIF-1 $\alpha$ expression, and its level is positively correlated with RV hypertrophy and PAP (118). Interestingly, mice with Hif2a gain-of-function mutations develop RV hypertrophy but do not show signs of RV dilatation despite a substantial increase in PAP, suggesting preserved RV function (107). In patients with repaired tetralogy of Fallot, the presence of gain-of-function mutations in HIF- $1 \alpha$ is associated with preserved RV function and better outcome due to increased TGF- 31 (TGFB1) expression and myocardial fibrosis (119). Collectively, these reports suggest that presumably mild to moderate activation of both HIFs is associated with preserved RV function. By contrast, strong activation of HIFs adversely affects RV function.
For example, mice with global inducible deletion of $P h d 2$ display increased mortality due to severe polycythemia and dilated cardiomyopathy (120). Similarly, HIF-2 activation in mice with ECspecific $P h d 2$ deletion leads to spontaneous $\mathrm{PH}$ with high mortality due to severe RV failure (10). However, the roles of HIFs and PHDs have not been studied in fixed-afterload models of RV hypertrophy and failure using cell-specific gene knockout or overexpression.

\section{Therapeutic potential of HIF targeting in $\mathrm{PH}$}

As we have discussed above, experiments in rodent models revealed that HIF- $1 / 2 \alpha$ exerts a profound impact on pulmonary vascular remodeling. Moreover, antisense oligonucleotides to Hif2 (but not to Hifl) reduced vessel muscularization, rises in PAPs, and RV hypertrophy in mice exposed to hypoxia, suggesting that inhibition of HIF- $2 \alpha$ can provide a therapeutic approach to prevent or reverse the development of PH (99). Thus, great interest has arisen in developing therapeutics targeting this pathway. Studies have specifically targeted components of the HIF pathway such as PHD2, HIF-1 $\alpha$, or HIF- $2 \alpha$ with pharmacological agents in various rodent models of PH. Most tested agents that directly or indirectly inhibit HIFs have been able to prevent or reverse experimental PH (Table 3). Agents/compounds that inhibit HIF$1 \alpha$ at the level of mRNA (topotecan and camptothecin), protein synthesis (2-methoxyestradiol, digoxin, celastramycin, caffeic acid phenethyl ester), protein accumulation and transcriptional activity (YC-1), and targeting of the molecules regulating the HIF 
axis (anti-CD146, mAb AA98, apigenin), or that inhibit HIF-2 $\alpha$ at the level of mRNA (C76) or at the level of heterodimerization and DNA binding (PT2567), have been evaluated. These inhibitors, given via different routes (intraperitoneal, intravenous, subcutaneous, oral), were shown to prevent as well as reverse $\mathrm{PH}$ in various animal models of PH (hypoxia, MCT, and SuHx). Notably, the HIF-2 $\alpha$ inhibitor $\mathrm{C} 76$ showed strong anti-remodeling effects in three experimental models of $\mathrm{PH}$ (27), indicating that inhibition of HIF-2 may be a promising therapeutic approach for $\mathrm{PH}$.

\section{Conclusions and future directions}

Data obtained from cell systems, animal models, and patientderived materials have consistently confirmed that HIF isoforms are important components of $\mathrm{PH}$ pathogenesis. The hypoxic and pseudohypoxic states that occur in different groups of $\mathrm{PH}$ may vary in intensity and duration, thus allowing an intricate interplay between HIF-1 and HIF-2 in driving the pathological processes that underlie pulmonary vascular and RV remodeling. Animal models have helped elucidate the nonredundant and complementary roles of HIF-1 and HIF-2. For example, HIF-1 plays a major role in driving vasoconstriction, PASMC proliferation, angiogenesis, and RV contractility, whereas HIF-2 plays a major role in inflammatory cell recruitment and in EC phenotypic switch to a proinflammatory state and to EndoMT. These data suggest dynamic regulation of HIF isoforms as well as cell- and context-specific roles of HIF-1 and HIF-2 in the initiation, progression, and establishment phases of pulmonary vascular and RV remodeling. Although head-tohead comparisons of mice with cell-specific deletions of HIF- $1 \alpha$ and HIF- $2 \alpha$ at different time points of hypoxic exposure are still needed to determine their influence on pulmonary vasculature and RV, it is conceivable that HIF- $2 \alpha$ may play a major role in the initiation of the disease, whereas HIF- $1 \alpha$ may play a major role in the progression and perpetuation of the disease. However, in cancers, HIF- $1 \alpha$ plays the dominant role in the response to acute hypoxia, whereas HIF-2 $\alpha$ drives the response to chronic hypoxia, although both are involved in cancer progression (121). Intriguingly, this HIF switch is also observed in pulmonary vascular endothelial and smooth muscle cells upon exposure to hypoxia (122), which may allow HIF-1 and HIF-2 to play divergent and complementary roles during hypoxic and pseudohypoxic responses of pulmonary vascular and cardiac cells in $\mathrm{PH}$.

These contradictory data in knockout mouse models versus in vitro cell models may be explained by the use of acute exposure to hypoxia (maximum exposure of 1-4 days) in the in vitro experiments versus the use of small-animal models (mice) for $\mathrm{PH}$ in the knockout studies. Thus, further studies with inducible deletion of HIF isoforms in severe animal models of $\mathrm{PH}$ (MCT, SuHx in mice and rats) and in vascular cells isolated from $\mathrm{PH}$ patients and large animals (cows), which exhibit and maintain their unique phenotypes in vitro (44), are needed to provide deeper insights into cell type- and context-specific roles of HIF isoforms in PH. Furthermore, understanding the molecular mechanisms that determine HIF-1/2 switches or activation of cell type- and context-specific HIF isoforms in PH will facilitate a better understanding of the pathophysiological roles exerted by HIF isoforms and the potential clinical implications of targeting them. For example, PHD2 has relatively more influence on HIF-1 $\alpha$, whereas PHD3 has rel- atively more influence on HIF-2 $\alpha$ (123). In addition, molecules like sirtuin 1, hypoxia-associated factor (HAF), and heat shock proteins (HSP70, HSP90) differentially regulated the degradation and activities of different HIF isoforms in various cell types $(121,124)$. Furthermore, translation of HIF- $2 \alpha$ (but not HIF-1 $\alpha$ ) is linked to iron metabolism due to an iron-responsive element in the $5^{\prime}$-untranslated region of HIF- $2 \alpha(125,126)$. However, no studies to date have explored the mechanisms regulating the HIF-1/2 switch in pulmonary vascular and cardiac cells upon exposure to hypoxia and other nonhypoxic PH stimuli. Considering the pathophysiological roles of iron metabolism, sirtuins, and heat shock proteins in $\mathrm{PH}(68,126-128)$, the possibility that these mechanisms are operative in the putative HIF-1/2 switch associated with PH warrants further investigation.

Despite striking similarity in protein sequence, dimerization partners, and binding sites among HIF- $1 \alpha$ and HIF- $2 \alpha$ proteins, it is well documented that HIF-1 and HIF-2 activate different subsets of hypoxia-inducible genes in various pathological conditions, including PH. Recent studies suggest that despite sharing an identical consensus recognition sequence, each HIF isoform has an inherent property that determines its binding distribution across the genome. For example, HIF-1 binds closer to promoters, while HIF-2 binds distal enhancers, and their inherent distributions are unaffected by the degree or duration of hypoxia or the cell type (129). In addition, differential recruitment of other transcription factors underlies HIF-mediated cell-specific hypoxia responses. Indeed, accumulating evidence suggests that HIF- $1 \alpha$ and HIF- $2 \alpha$ form separate multifactorial complexes with other transcription factors, cofactors, and RNA polymerase II to mediate the distinct functions of HIF-1 or HIF-2 (130). Hence, it is important to identify these complexes and their common and unique target genes, not only to understand the distinct pathological processes mediated by HIF isoforms, but also to selectively inhibit HIF isoform functions as a therapeutic approach.

In summary, rapidly advancing research has brought to light the isoform-specific, context-specific, and cell-specific roles of the HIF pathway in regulating pulmonary vascular remodeling. This has introduced a novel therapeutic approach for the treatment of $\mathrm{PH}$. Inline, HIF-2-selective inhibitors reversed $\mathrm{PH}$ in various animal models of $\mathrm{PH}$ without any significant side effects. Notably, a HIF-2-specific small-molecule inhibitor developed to treat renal cancer has demonstrated a favorable safety profile in a recent phase I trial (131), entered into phase II clinical trials, and will be considered for clinical trials among $\mathrm{PH}$ patients in the future. Head-to-head comparisons and multicenter preclinical studies of pan-HIF inhibitors and HIF-1- and HIF-2-selective inhibitors in various animal models of $\mathrm{PH}$ and $\mathrm{RV}$ dysfunction are warranted before moving into clinical development (132). Notably, further studies are needed to develop personalized therapeutics, i.e., to determine under what conditions and in which $\mathrm{PH}$ patients HIF inhibition can provide an optimal therapeutic strategy. In addition, given the myriad roles of HIFs and their possible influence on extrapulmonary manifestations in patients with $\mathrm{PH}(15,133)$, it will be important to carefully assess the risk/benefit ratio of systemic versus pulmonary selective HIF inhibitors. Thus, more work needs to be done to identify novel, potent, and more specific inhibitors targeting clearly defined points in the HIF pathway, followed by 
lung-selective delivery of these inhibitors, which will be the key to developing potential therapeutic strategies for $\mathrm{PH}$.

\section{Acknowledgments}

This work was funded by the Deutsche Forschungsgemeinschaft (DFG, German Research Foundation), Projektnummer 268555672, SFB 1213, project A01, A05, A06 and A10* grants and a European Research Council (ERC) Consolidator Grant (866051 to SSP).

Address correspondence to: Soni Savai Pullamsetti, Max Planck Institute for Heart and Lung Research, Parkstraße 1, $61231 \mathrm{Bad}$ Nauheim, Germany. Phone: 49.6032.705.380; Email: soni. pullamsetti@mpi-bn.mpg.de.
1. Prabhakar NR, Semenza GL. Adaptive and maladaptive cardiorespiratory responses to continuous and intermittent hypoxia mediated by hypoxia-inducible factors 1 and 2. Physiol Rev. 2012;92(3):967-1003.

2. Semenza GL. Oxygen sensing, hypoxia-inducible factors, and disease pathophysiology. Annu Rev Pathol. 2014;9:47-71.

3. Pullamsetti SS, Savai R, Seeger W, Goncharova EA. Translational advances in the field of pulmonary hypertension. From cancer biology to new pulmonary arterial hypertension therapeutics. Targeting cell growth and proliferation signaling hubs. Am J Respir Crit Care Med. 2017;195(4):425-437.

4. Humbert M, et al. Pathology and pathobiology of pulmonary hypertension: state of the art and research perspectives. Eur Respir J. 2019;53(1):1801887.

5. Neupane M, Swenson ER. High-altitude pulmonary vascular diseases. Adv Pulm Hypertens. 2017;15(3):149-157.

6. Wilkins MR, Ghofrani HA, Weissmann N, Aldashev A, Zhao L. Pathophysiology and treatment of high-altitude pulmonary vascular disease. Circulation. 2015;131(6):582-590.

7. Fu X, Zhang F. Role of the HIF-1 signaling pathway in chronic obstructive pulmonary disease. Exp Ther Med. 2018;16(6):4553-4561.

8. Aquino-Galvez A, et al. Dysregulated expression of hypoxia-inducible factors augments myofibroblasts differentiation in idiopathic pulmonary fibrosis. Respir Res. 2019;20(1):130.

9. Bonnet S, et al. An abnormal mitochondrialhypoxia inducible factor-1alpha-Kv channel pathway disrupts oxygen sensing and triggers pulmonary arterial hypertension in fawn hooded rats: similarities to human pulmonary arterial hypertension. Circulation. 2006;113(22):2630-2641.

10. Dai Z, Li M, Wharton J, Zhu MM, Zhao YY. Prolyl-4 hydroxylase 2 (PHD2) deficiency in endothelial cells and hematopoietic cells induces obliterative vascular remodeling and severe pulmonary arterial hypertension in mice and humans through hypoxia-inducible factor- $2 \alpha$. Circulation. 2016;133(24):2447-2458.

11. Lei W, et al. Expression and analyses of the HIF-1 pathway in the lungs of humans with pulmonary arterial hypertension. Mol Med Rep. 2016;14(5):4383-4390.

12. El Kasmi KC, et al. Adventitial fibroblasts induce a distinct proinflammatory/profibrotic macrophage phenotype in pulmonary hypertension. J Immunol. 2014;193(2):597-609.

13. Tuder RM, et al. Expression of angiogenesisrelated molecules in plexiform lesions in severe pulmonary hypertension: evidence for a process of disordered angiogenesis. JPathol.
2001;195(3):367-374.

14. Wang M, et al. miRNA-PDGFRB/HIF1A-lncRNA CTEPHA1 network plays important roles in the mechanism of chronic thromboembolic pulmonary hypertension. Int Heart J. 2019;60(4):924-937.

15. Garcia-Morales LJ, et al. Altered hypoxicadenosine axis and metabolism in group III pulmonary hypertension. Am J Respir Cell Mol Biol. 2016;54(4):574-583.

16. Bryant AJ, et al. Endothelial HIF signaling regulates pulmonary fibrosis-associated pulmonary hypertension. Am J Physiol Lung Cell Mol Physiol. 2016;310(3):L249-L262.

17. Huang Y, et al. Hypoxia inducible factor $2 \alpha$ (HIF2 $\alpha$ /EPAS1) is associated with development of pulmonary hypertension in severe congenital diaphragmatic hernia patients. Pulm Circ. 2018;8(3):2045894018783734.

18. Han CF, Li ZY, Li TH. Roles of hypoxia-inducible factor- $1 \alpha$ and its target genes in neonatal hypoxic pulmonary hypertension. Eur Rev Med Pharmacol Sci. 2017;21(18):4167-4180.

19. Lemus-Varela ML, et al. Expression of HIF-1 alpha, VEGF and EPO in peripheral blood from patients with two cardiac abnormalities associated with hypoxia. Clin Biochem. 2010;43(3):234-239.

20. Farha $S$, et al. Hypoxia-inducible factors in human pulmonary arterial hypertension: a link to the intrinsic myeloid abnormalities. Blood. 2011;117(13):3485-3493.

21. Fijalkowska I, et al. Hypoxia inducible-factor1alpha regulates the metabolic shift of pulmonary hypertensive endothelial cells. Am J Pathol. 2010;176(3):1130-1138.

22. Kurosawa R, et al. Identification of celastramycin as a novel therapeutic agent for pulmonary arterial hypertension. Circ Res. 2019;125(3):309-327.

23. Marsboom G, et al. Dynamin-related protein 1-mediated mitochondrial mitotic fission permits hyperproliferation of vascular smooth muscle cells and offers a novel therapeutic target in pulmonary hypertension. Circ Res. 2012;110(11):1484-1497.

24. Labrousse-Arias D, et al. HIF-2 $\alpha$-mediated induction of pulmonary thrombospondin-1 contributes to hypoxia-driven vascular remodelling and vasoconstriction. Cardiovasc Res. 2016;109(1):115-130.

25. Wang CC, et al. Pulmonary artery smooth muscle cell HIF- $1 \alpha$ regulates endothelin expression via microRNA-543. Am J Physiol Lung Cell Mol Physiol. 2018;315(3):L422-L431.

26. Barnes EA, Chen CH, Sedan O, Cornfield DN. Loss of smooth muscle cell hypoxia inducible factor- $1 \alpha$ underlies increased vascular contractility in pulmonary hypertension. FASEB J. 2017;31(2):650-662.

27. Dai $Z$, et al. Therapeutic targeting of vascular remodeling and right heart failure in pulmonary arterial hypertension with a HIF- $2 \alpha$ inhibitor. Am J Respir Crit Care Med. 2018;198(11):1423-1434.

28. Tang H, et al. Endothelial HIF-2 $\alpha$ contributes to severe pulmonary hypertension due to endothelialto-mesenchymal transition. Am J Physiol Lung Cell Mol Physiol. 2018;314(2):L256-L275.

29. Ang SO, et al. Endemic polycythemia in Russia: mutation in the VHL gene. Blood Cells Mol Dis. 2002;28(1):57-62.

30. Sarangi S, et al. The homozygous VHL(D126N) missense mutation is associated with dramatically elevated erythropoietin levels, consequent polycythemia, and early onset severe pulmonary hypertension. Pediatr Blood Cancer. 2014;61(11):2104-2106.

31. Bond J, et al. Dysregulation of the HIF pathway due to VHL mutation causing severe erythrocytosis and pulmonary arterial hypertension. Blood. 2011;117(13):3699-3701.

32. Caravita S, Deboeck G, Vachiery JL, Naeije R. Pulmonary arterial hypertension associated with a von Hippel-Lindau gene mutation. J Heart Lung Transplant. 2016;35(9):1138-1139.

33. Bushuev VI, et al. Endothelin-1, vascular endothelial growth factor and systolic pulmonary artery pressure in patients with Chuvash polycythemia. Haematologica. 2006;91(6):744-749.

34. Dham N, et al. Prospective assessment of pulmonary hypertension in children with Chuvash polycythemia. Blood. 2007;110(11):3665.

35. Sable CA, et al. Pulmonary artery pressure and iron deficiency in patients with upregulation of hypoxia sensing due to homozygous VHL(R200W) mutation (Chuvash polycythemia). Haematologica. 2012;97(2):193-200.

36. Gale DP, Harten SK, Reid CD, Tuddenham EG, Maxwell PH. Autosomal dominant erythrocytosis and pulmonary arterial hypertension associated with an activating HIF2 alpha mutation. Blood. 2008;112(3):919-921.

37. Penaloza D, Arias-Stella J. The heart and pulmonary circulation at high altitudes: healthy highlanders and chronic mountain sickness. Circulation. 2007;115(9):1132-1146.

38. Peng Y, et al. Down-regulation of EPAS1 transcription and genetic adaptation of Tibetans to high-altitude hypoxia. Mol Biol Evol. 2017;34(4):818-830.

39. Petousi $\mathrm{N}$, et al. Tibetans living at sea level have a hyporesponsive hypoxia-inducible factor system and blunted physiological responses to hypoxia. J Appl Physiol (1985). 2013;116(7):893-904.

40. Fish JE, et al. Hypoxia-inducible expression of a natural cis-antisense transcript inhibits endothelial nitric-oxide synthase. J Biol Chem. 2007;282(21):15652-15666.

41. Cattaneo MG, et al. Chronic deficiency of nitric 
oxide affects hypoxia inducible factor-1 $\alpha$ (HIF$1 \alpha)$ stability and migration in human endothelial cells. PLoS One. 2011;6(12):e29680.

42. BelAiba RS, et al. Redox-sensitive regulation of the HIF pathway under non-hypoxic conditions in pulmonary artery smooth muscle cells. Biol Chem. 2004;385(3-4):249-257.

43. Sun X, et al. Endothelin-1 induces a glycolytic switch in pulmonary arterial endothelial cells via the mitochondrial translocation of endothelial nitric oxide synthase. Am J Respir Cell Mol Biol. 2014;50(6):1084-1095.

44. Pisarcik S, et al. Activation of hypoxia-inducible factor-1 in pulmonary arterial smooth muscle cells by endothelin-1. Am J Physiol Lung Cell Mol Physiol. 2013;304(8):L549-L561.

45. Li M, et al. Endothelin-1 induces hypoxia inducible factor $1 \alpha$ expression in pulmonary artery smooth muscle cells. FEBS Lett. 2012;586(21):3888-3893.

46. Yamashita T, et al. Abnormal heart development and lung remodeling in mice lacking the hypoxia-inducible factor-related basic helixloop-helix PAS protein NEPAS. Mol Cell Biol. 2008;28(4):1285-1297.

47. Liu J, et al. IL-33 initiates vascular remodelling in hypoxic pulmonary hypertension by up-regulating HIF-1 $\alpha$ and VEGF expression in vascular endothelial cells. EBioMedicine. 2018;33:196-210.

48. Li C, Mpollo MS, Gonsalves CS, Tahara SM, Malik P, Kalra VK. Peroxisome proliferatoractivated receptor- $\alpha$-mediated transcription of miR-199a2 attenuates endothelin-1 expression via hypoxia-inducible factor-1 $\alpha$. J Biol Chem. 2014;289(52):36031-36047.

49. Patel N, Gonsalves CS, Malik P, Kalra VK. Placenta growth factor augments endothelin-1 and endothelin-B receptor expression via hypoxia-inducible factor-1 alpha. Blood. 2008;112(3):856-865.

50. Gonsalves CS, et al. Erythropoietin-mediated expression of placenta growth factor is regulated via activation of hypoxia-inducible factor- $1 \alpha$ and post-transcriptionally by miR-214 in sickle cell disease. Biochem J. 2015;468(3):409-423.

51. Earley S, Resta TC. Estradiol attenuates hypoxiainduced pulmonary endothelin-1 gene expression. Am J Physiol Lung Cell Mol Physiol. 2002;283(1):L86-L93.

52. Frump AL, et al. Hypoxia upregulates estrogen receptor $\beta$ in pulmonary artery endothelial cells in a HIF-1 $\alpha$-dependent manner. Am J Respir Cell Mol Biol. 2018;59(1):114-126.

53. Morikawa M, et al. The ALK-1/SMAD/ATOH8 axis attenuates hypoxic responses and protects against the development of pulmonary arterial hypertension. Sci Signal. 2019;12(607):eaay4430.

54. Ghosh G, et al. Hypoxia-induced microRNA-424 expression in human endothelial cells regulates HIF- $\alpha$ isoforms and promotes angiogenesis. J Clin Invest. 2010;120(11):4141-4154.

55 . Luo Y, et al. CD146-HIF-1 $\alpha$ hypoxic reprogramming drives vascular remodeling and pulmonary arterial hypertension. Nat Commun. 2019;10(1):3551.

56. Schultz K, Fanburg BL, Beasley D. Hypoxia and hypoxia-inducible factor-1alpha promote growth factor-induced proliferation of human vascular smooth muscle cells. Am J Physiol Heart Circ
Physiol. 2006;290(6):H2528-H2534.

57. Blum JI, Bijli KM, Murphy TC, Kleinhenz JM, Hart CM. Time-dependent PPAR $\gamma$ modulation of HIF-1 $\alpha$ signaling in hypoxic pulmonary artery smooth muscle cells. Am JMed Sci. 2016;352(1):71-79.

58. Wang Y, et al. Peroxisome proliferator-activated receptor $\gamma$ inhibits pulmonary hypertension targeting store-operated calcium entry. J Mol Med (Berl). 2015;93(3):327-342.

59. Yue J, et al. MicroRNA-206 is involved in hypoxiainduced pulmonary hypertension through targeting of the HIF- $1 \alpha /$ Fhl-1 pathway. Lab Invest. 2013;93(7):748-759.

60. Chen M, Shen C, Zhang Y, Shu H. MicroRNA-150 attenuates hypoxia-induced excessive proliferation and migration of pulmonary arterial smooth muscle cells through reducing HIF-1 $\alpha$ expression. Biomed Pharmacother. 2017;93:861-868.

61. Jiang Y, et al. Increased SUMO-1 expression in response to hypoxia: interaction with HIF-1 $\alpha$ in hypoxic pulmonary hypertension. Int J Mol Med. 2015;36(1):271-281.

62. Zhou F, Dai A, Jiang Y, Tan X, Zhang X. SENP-1 enhances hypoxia-induced proliferation of rat pulmonary artery smooth muscle cells by regulating hypoxia-inducible factor-1 $\alpha$. Mol Med Rep. 2016;13(4):3482-3490.

63. Pak O, et al. Impact of the mitochondriatargeted antioxidant MitoQ on hypoxiainduced pulmonary hypertension. Eur Respir J. 2018;51:1701024.

64. Veit F, et al. Function of NADPH oxidase 1 in pulmonary arterial smooth muscle cells after monocrotaline-induced pulmonary vascular remodeling. Antioxid Redox Signal. 2013;19(18):2213-2231.

65. Goyal P, et al. Upregulation of NAD(P)H oxidase 1 in hypoxia activates hypoxia-inducible factor 1 via increase in reactive oxygen species. Free Radic Biol Med. 2004;36(10):1279-1288.

66. Sommer N, Strielkov I, Pak O, Weissmann N. Oxygen sensing and signal transduction in hypoxic pulmonary vasoconstriction. Eur Respir J. 2016;47(1):288-303.

67. Wedgwood S, Lakshminrusimha S, Schumacker PT, Steinhorn RH. Hypoxia inducible factor signaling and experimental persistent pulmonary hypertension of the newborn. Front Pharmacol. 2015;6(47):47.

68. Paulin R, et al. Sirtuin 3 deficiency is associated with inhibited mitochondrial function and pulmonary arterial hypertension in rodents and humans. Cell Metab. 2014;20(5):827-839.

69. Dabral S, et al. A RASSF1A-HIF1 $\alpha$ loop drives Warburg effect in cancer and pulmonary hypertension. Nat Commun. 2019;10(1):2130.

70. He M, et al. Hypoxia induces the dysfunction of human endothelial colony-forming cells via HIF-1 $\alpha$ signaling. Respir Physiol Neurobiol. 2018;247:87-95.

71. Bertero T, et al. Systems-level regulation of microRNA networks by miR-130/301 promotes pulmonary hypertension. J Clin Invest. 2014;124(8):3514-3528.

72. Marín-Hernández A, Gallardo-Pérez JC, Ralph SJ, Rodríguez-Enríquez S, Moreno-Sánchez R. HIF-1alpha modulates energy metabolism in cancer cells by inducing over-expression of specific glycolytic isoforms. Mini Rev Med Chem. 2009;9(9):1084-1101.

73. Cowburn AS, et al. HIF $2 \alpha$-arginase axis is essential for the development of pulmonary hypertension. Proc Natl Acad Sci U S A. 2016;113(31):8801-8806.

74. Krotova K, Patel JM, Block ER, Zharikov S. Hypoxic upregulation of arginase II in human lung endothelial cells. Am J Physiol Cell Physiol. 2010;299(6):C1541-1548.

75. Jung $\mathrm{C}$, et al. Arginase inhibition reverses monocrotaline-induced pulmonary hypertension. Int $J$ Mol Sci. 2017;18(8):1609.

76. Skuli N, et al. Endothelial HIF-2 $\alpha$ regulates murine pathological angiogenesis and revascularization processes. JClin Invest. 2012;122(4):1427-1443.

77. Jiang $X$, et al. Endothelial hypoxia-inducible factor- $2 \alpha$ is required for the maintenance of airway microvasculature. Circulation. 2019;139(4):502-517.

78. Shan F, Li J, Huang QY. HIF-1 alpha-induced up-regulation of miR-9 contributes to phenotypic modulation in pulmonary artery smooth muscle cells during hypoxia. J Cell Physiol. 2014;229(10):1511-1520.

79. Zeng Y, et al. Hypoxia inducible factor-1 mediates expression of miR-322: potential role in proliferation and migration of pulmonary arterial smooth muscle cells. Sci Rep. 2015;5:12098.

80. Gou D, et al. miR-210 has an antiapoptotic effect in pulmonary artery smooth muscle cells during hypoxia. Am J Physiol Lung Cell Mol Physiol. 2012;303(8):L682-L691.

81. Labrousse-Arias D, et al. HIF-2 $\alpha$-mediated induction of pulmonary thrombospondin- 1 contributes to hypoxia-driven vascular remodelling and vasoconstriction. Cardiovasc Res. 2016;109(1):115-130

82. Sheikh AQ, Lighthouse JK, Greif DM. Recapitulation of developing artery muscularization in pulmonary hypertension. Cell Rep. 2014;6(5):809-817.

83. Sheikh AQ, Misra A, Rosas IO, Adams RH, Greif DM. Smooth muscle cell progenitors are primed to muscularize in pulmonary hypertension. Sci Transl Med. 2015;7(308):308ra159.

84. Sheikh AQ, Saddouk FZ, Ntokou A, Mazurek R, Greif DM. Cell autonomous and non-cell autonomous regulation of SMC progenitors in pulmonary hypertension. Cell Rep. 2018;23(4):1152-1165.

85. Wang J, Weigand L, Lu W, Sylvester JT, Semenza GL, Shimoda LA. Hypoxia inducible factor 1 mediates hypoxia-induced TRPC expression and elevated intracellular $\mathrm{Ca} 2+$ in pulmonary arterial smooth muscle cells. Circ Res. 2006;98(12):1528-1537.

86. Whitman EM, et al. Endothelin-1 mediates hypoxia-induced inhibition of voltage-gated $\mathrm{K}+$ channel expression in pulmonary arterial myocytes. Am J Physiol Lung Cell Mol Physiol. 2008;294(2):L309-L318.

87. Ahn YT, Kim YM, Adams E, Lyu SC, Alvira CM, Cornfield DN. Hypoxia-inducible factor-1 $\alpha$ regulates KCNMB1 expression in human pulmonary artery smooth muscle cells. Am J Physiol Lung Cell Mol Physiol. 2012;302(3):L352-L359.

88. Eul B, et al. Impact of HIF-1alpha and HIF-2alpha on proliferation and migration of human pulmonary artery fibroblasts in hypoxia. FASEB $J$. 2006;20(1):163-165. 
89. Krick S, et al. Hypoxia-driven proliferation of human pulmonary artery fibroblasts: cross-talk between HIF-1alpha and an autocrine angiotensin system. FASEB J. 2005;19(7):857-859.

90. Zhang R, et al. Role of HIF-1alpha in the regulation ACE and ACE2 expression in hypoxic human pulmonary artery smooth muscle cells. Am JPhysiol Lung Cell Mol Physiol. 2009;297(4):L631-L640.

91. Zhang R, et al. MiRNA let-7b promotes the development of hypoxic pulmonary hypertension by targeting ACE2. Am J Physiol Lung Cell Mol Physiol. 2019;316(3):L547-L557.

92. Rabinovitch M, Guignabert C, Humbert M, Nicolls MR. Inflammation and immunity in the pathogenesis of pulmonary arterial hypertension. Circ Res. 2014;115(1):165-175.

93. Takeda K, Ho VC, Takeda H, Duan LJ, Nagy A, Fong GH. Placental but not heart defects are associated with elevated hypoxia-inducible factor alpha levels in mice lacking prolyl hydroxylase domain protein 2. Mol Cell Biol. 2006;26(22):8336-8346.

94. Iyer NV, et al. Cellular and developmental control of $\mathrm{O} 2$ homeostasis by hypoxia-inducible factor 1 alpha. Genes Dev. 1998;12(2):149-162.

95. Tian H, Hammer RE, Matsumoto AM, Russell DW, McKnight SL. The hypoxia-responsive transcription factor EPAS1 is essential for catecholamine homeostasis and protection against heart failure during embryonic development. Genes Dev. 1998;12(21):3320-3324.

96. Maltepe E, Schmidt JV, Baunoch D, Bradfield CA, Simon MC. Abnormal angiogenesis and responses to glucose and oxygen deprivation in mice lacking the protein ARNT. Nature. 1997;386(6623):403-407.

97. Yu AY, et al. Impaired physiological responses to chronic hypoxia in mice partially deficient for hypoxia-inducible factor 1alpha. JClin Invest. 1999;103(5):691-696.

98. Brusselmans K, et al. Heterozygous deficiency of hypoxia-inducible factor-2alpha protects mice against pulmonary hypertension and right ventricular dysfunction during prolonged hypoxia. JClin Invest. 2003;111(10):1519-1527.

99. Hu CJ, et al. Suppression of HIF2 signalling attenuates the initiation of hypoxia-induced pulmonary hypertension. Eur Respir J. 2019;54(6):1900378.

100.Ball MK, et al. Regulation of hypoxia-induced pulmonary hypertension by vascular smooth muscle hypoxia-inducible factor-1 $\alpha$. Am J Respir Crit Care Med. 2014;189(3):314-324.

101. Kim YM, Barnes EA, Alvira CM, Ying L, Reddy S, Cornfield DN. Hypoxia-inducible factor-1 $\alpha$ in pulmonary artery smooth muscle cells lowers vascular tone by decreasing myosin light chain phosphorylation. Circ Res. 2013;112(9):1230-1233.

102. Tang H, et al. Endothelial HIF-2 $\alpha$ contributes to severe pulmonary hypertension due to endothelial-to-mesenchymal transition. Am J Physiol Lung Cell Mol Physiol. 2018;314(2):L256-L275.

103. Skuli N, et al. Endothelial deletion of hypoxiainducible factor-2alpha (HIF-2alpha) alters vascular function and tumor angiogenesis. Blood. 2009;114(2):469-477.

104.Payne S, De Val S, Neal A. Endothelial-specific Cre mouse models. Arterioscler Thromb Vasc Biol.
2018;38(11):2550-2561.

105. Kapitsinou PP, et al. The endothelial prolyl-4hydroxylase domain 2 /hypoxia-inducible factor 2 axis regulates pulmonary artery pressure in mice. Mol Cell Biol. 2016;36(10):1584-1594.

106. Wang S, et al. Loss of prolyl hydroxylase domain protein 2 in vascular endothelium increases pericyte coverage and promotes pulmonary arterial remodeling. Oncotarget. 2016;7(37):58848-58861.

107. Tan Q, et al. Erythrocytosis and pulmonary hypertension in a mouse model of human HIF2A gain of function mutation. J Biol Chem. 2013;288(24):17134-17144.

108. Hickey MM, et al. The von Hippel-Lindau Chuvash mutation promotes pulmonary hypertension and fibrosis in mice. JClin Invest. 2010;120(3):827-839.

109. Kojima $\mathrm{H}$, et al. Hypoxia-inducible factor-1 $\alpha$ deletion in myeloid lineage attenuates hypoxiainduced pulmonary hypertension. Physiol Rep. 2019;7(7):e14025.

110. Yu YA, et al. Nonclassical monocytes sense hypoxia, regulate pulmonary vascular remodeling, and promote pulmonary hypertension. JImmunol. 2020;204(6):1474-1485.

111. Yamamoto A, et al. Systemic silencing of PHD2 causes reversible immune regulatory dysfunction. J Clin Invest. 2019;129(9):3640-3656.

112. Tamosiuniene $\mathrm{R}$, et al. Regulatory $\mathrm{T}$ cells limit vascular endothelial injury and prevent pulmonary hypertension. Circ Res. 2011;109(8):867-879.

113. Lahm T, et al. Assessment of right ventricular function in the research setting: knowledge gaps and pathways forward. An official American Thoracic Society research statement. Am J Respir Crit Care Med. 2018;198(4):e15-e43.

114. Tekin D, Dursun AD, Bastug M, Karaorman G, Ficicilar $\mathrm{H}$. The effects of acute and intermittent hypoxia on the expressions of HIF-1 $\alpha$ and VEGF in the left and right ventricles of the rabbit heart. Anadolu Kardiyol Derg. 2011;11(5):379-385.

115. Adao R, et al. Urocortin-2 improves right ventricular function and attenuates pulmonary arterial hypertension. Cardiovasc Res. 2018;114(8):1165-1177.

116. Zhang S, et al. Stabilization of hypoxia-inducible factor by DMOG inhibits development of chronic hypoxia-induced right ventricular remodeling. J Cardiovasc Pharmacol. 2016;67(1):68-75.

117. Bogaard HJ, et al. Chronic pulmonary artery pressure elevation is insufficient to explain right heart failure. Circulation. 2009;120(20):1951-1960.

118. Liu W, Zhang Y, Lu L, Wang L, Chen M, Hu T. Expression and correlation of hypoxia-inducible factor-1 $\alpha$ (HIF-1 $\alpha)$ with pulmonary artery remodeling and right ventricular hypertrophy in experimental pulmonary embolism. Med Sci Monit. 2017;23:2083-2088.

119. Jeewa A, et al. Genetic determinants of rightventricular remodeling after tetralogy of Fallot repair. Pediatr Res. 2012;72(4):407-413.

120. Minamishima YA, et al. Somatic inactivation of the PHD2 prolyl hydroxylase causes polycythemia and congestive heart failure. Blood. 2008;111(6):3236-3244.

121. Koh MY, Lemos R, Liu X, Powis G. The hypoxiaassociated factor switches cells from HIF-1 $\alpha$ - to HIF-2 $\alpha$-dependent signaling promoting stem cell characteristics, aggressive tumor growth and invasion. Cancer Res. 2011;71(11):4015-4027.

122. Bartoszewski R, et al. Primary endothelial cell-specific regulation of hypoxia-inducible factor (HIF)- 1 and HIF-2 and their target gene expression profiles during hypoxia. FASEB $J$. 2019;33(7):7929-7941.

123. Appelhoff RJ, et al. Differential function of the prolyl hydroxylases PHD1, PHD2, and PHD3 in the regulation of hypoxia-inducible factor. $J$ Biol Chem. 2004;279(37):38458-38465.

124. Koh MY, Powis G. Passing the baton: the HIF switch. Trends Biochem Sci. 2012;37(9):364-372.

125. Rankin EB, et al. Hypoxia-inducible factor-2 (HIF-2) regulates hepatic erythropoietin in vivo. JClin Invest. 2007;117(4):1068-1077.

126.Sanchez M, Galy B, Muckenthaler MU, Hentze MW. Iron-regulatory proteins limit hypoxiainducible factor-2alpha expression in iron deficiency. Nat Struct Mol Biol. 2007;14(5):420-426.

127. Lim JH, Lee YM, Chun YS, Chen J, Kim JE, Park JW. Sirtuin 1 modulates cellular responses to hypoxia by deacetylating hypoxia-inducible factor 1alpha. Mol Cell. 2010;38(6):864-878.

128. Liu YV, Baek JH, Zhang H, Diez R, Cole RN, Semenza GL. RACK1 competes with HSP90 for binding to HIF-1alpha and is required for $\mathrm{O}(2)$-independent and HSP9O inhibitorinduced degradation of HIF-1alpha. Mol Cell. 2007;25(2):207-217.

129.Smythies JA, et al. Inherent DNA-binding specificities of the HIF- $1 \alpha$ and HIF- $2 \alpha$ transcription factors in chromatin. EMBO Rep. 2019;20(1):e46401.

130. Pawlus MR, Hu CJ. Enhanceosomes as integrators of hypoxia inducible factor (HIF) and other transcription factors in the hypoxic transcriptional response. Cell Signal. 2013;25(9):1895-1903.

131. Courtney KD, et al. Phase I dose-escalation trial of PT2385, a first-in-class hypoxia-inducible factor-2 $\alpha$ antagonist in patients with previously treated advanced clear cell renal cell carcinoma. JClin Oncol. 2018;36(9):867-874.

132. Provencher S, et al. Standards and methodological rigor in pulmonary arterial hypertension preclinical and translational research. Circ Res. 2018;122(7):1021-1032.

133. Nickel NP, et al. Beyond the lungs: systemic manifestations of pulmonary arterial hypertension. Am J Respir Crit Care Med. 2020;201(2):148-157.

134. Chen T, et al. miR-17/20 controls prolyl hydroxylase 2 (PHD2)/hypoxia-inducible factor 1 (HIF1) to regulate pulmonary artery smooth muscle cell proliferation. J Am Heart Assoc. 2016;5(12):e004510.

135. Deng B, et al. MicroRNA-103/107 is involved in hypoxia-induced proliferation of pulmonary arterial smooth muscle cells by targeting HIF-1 $\beta$. Life Sci. 2016;147:117-124.

136. Liu P, et al. Inhibition of Src activation reverses pulmonary vascular remodeling in experimental pulmonary arterial hypertension via Akt/ mTOR/HIF-1 signaling pathway. Exp Cell Res. 2019;380(1):36-46.

137. Yao L, et al. Reciprocal regulation of HIF-1 $\alpha$ and 15-LO/15-HETE promotes anti-apoptosis process in pulmonary artery smooth muscle cells during hypoxia. Prostaglandins Other Lipid Mediat. 2012;99(3-4):96-106. 
138. Li X, et al. KLF5 mediates vascular remodeling via HIF-1 $\alpha$ in hypoxic pulmonary hypertension. Am J Physiol Lung Cell Mol Physiol. 2016;310(4):L299-L310.

139. Diebold I, et al. Reciprocal regulation of Rac1 and PAK-1 by HIF-1alpha: a positive-feedback loop promoting pulmonary vascular remodeling. Antioxid Redox Signal. 2010;13(4):399-412.

140. Fukai K, et al. Pyk2 aggravates hypoxiainduced pulmonary hypertension by activating HIF-1a. Am J Physiol Heart Circ Physiol. 2015;308(8):H951-H959.

141. Pekarova M, et al. Asymmetric dimethyl arginine induces pulmonary vascular dysfunction via activation of signal transducer and activator of transcription 3 and stabilization of hypoxiainducible factor 1-alpha. Vascul Pharmacol. 2015;73:138-148.

142. Michaud MD, Robitaille GA, Gratton JP, Richard DE. Sphingosine-1-phosphate: a novel nonhypoxic activator of hypoxia-inducible factor-1 in vascular cells. Arterioscler Thromb Vasc Biol. 2009;29(6):902-908.

143. Zhang Z, Li Z, Wang Y, Wei L, Chen H. Overex- pressed long noncoding RNA CPS1-IT alleviates pulmonary arterial hypertension in obstructive sleep apnea by reducing interleukin- $1 \beta$ expression via HIF1 transcriptional activity. J Cell Physiol. 2019;234(11):19715-19727.

144.Ghosh MC, et al. Deletion of iron regulatory protein 1 causes polycythemia and pulmonary hypertension in mice through translational derepression of HIF2 $\alpha$. Cell Metab. 2013;17(2):271-281.

145. Johns RA, et al. Hypoxia-inducible factor $1 \alpha$ is a critical downstream mediator for hypoxiainduced mitogenic factor (FIZZ1/RELM $\alpha$ )induced pulmonary hypertension. Arterioscler Thromb Vasc Biol. 2016;36(1):134-144.

146.Song D, et al. Tibetan PHD2, an allele with lossof-function properties. Proc Natl Acad Sci U S A. 2020;117(22):12230-12238.

147. Macias D, Cowburn AS, Torres-Torrelo H, OrtegaSáenz P, López-Barneo J, Johnson RS. HIF-2 $\alpha$ is essential for carotid body development and function. Elife. 2018;7:e34681.

148. Docherty CK, Nilsen M, MacLean MR. Influence of 2-methoxyestradiol and sex on hypoxia-induced pulmonary hypertension and hypoxia-inducible factor-1- $\alpha$. J Am Heart Assoc. 2019;8(5):e011628.

149. Jiang Y, et al. Topotecan prevents hypoxia-induced pulmonary arterial hypertension and inhibits hypoxia-inducible factor-1 $\alpha$ and TRPC channels. Int J Biochem Cell Biol. 2018;104:161-170.

150. Abud EM, et al. Digoxin inhibits development of hypoxic pulmonary hypertension in mice. Proc Natl Acad Sci U S A. 2012;109(4):1239-1244.

151. Cheng C-C, et al. Caffeic acid phenethyl ester rescues pulmonary arterial hypertension through the inhibition of AKT/ERK-dependent PDGF/HIF-1 $\alpha$ in vitro and in vivo. Int JMol Sci. 2019;20(6):1468.

152. Huh JW, Kim SY, Lee JH, Lee YS. YC-1 attenuates hypoxia-induced pulmonary arterial hypertension in mice. Pulm Pharmacol Ther. 2011;24(6):638-646.

153. He Y, Fang X, Shi J, Li X, Xie M, Liu X. Apigenin attenuates pulmonary hypertension by inducing mitochondria-dependent apoptosis of PASMCs via inhibiting the hypoxia inducible factor $1 \alpha-K V 1.5$ channel pathway. Chem Biol Interact. 2020;317:108942. 